\title{
Microglia Play an Active Role in Obesity-Associated Cognitive Decline
}

\author{
(D) Elise C. Cope, Elizabeth A. LaMarca, ${ }^{\star}$ PPatrick K. Monari, ${ }^{\star}$ Lyra B. Olson, Susana Martinez, Anna D. Zych, \\ -Nicole J. Katchur, and $\mathbb{C E}^{-E l i z a b e t h}$ Gould \\ Princeton Neuroscience Institute and Department of Psychology, Princeton University, Princeton, New Jersey 08544
}

Obesity affects $>600$ million people worldwide, a staggering number that appears to be on the rise. One of the lesser known consequences of obesity is its deleterious effects on cognition, which have been well documented across many cognitive domains and age groups. To investigate the cellular mechanisms that underlie obesity-associated cognitive decline, we used diet-induced obesity in male mice and found memory impairments along with reductions in dendritic spines, sites of excitatory synapses, increases in the activation of microglia, the brain's resident immune cells, and increases in synaptic profiles within microglia, in the hippocampus, a brain region linked to cognition. We found that partial knockdown of the receptor for fractalkine, a chemokine that can serve as a "find me" cue for microglia, prevented microglial activation and cognitive decline induced by obesity. Furthermore, we found that pharmacological inhibition of microglial activation in obese mice was associated with prevention of both dendritic spine loss and cognitive degradation. Finally, we observed that pharmacological blockade of microglial phagocytosis lessened obesity-associated cognitive decline. These findings suggest that microglia play an active role in obesity-associated cognitive decline by phagocytosis of synapses that are important for optimal function.

Key words: cognition; dendritic spine; microglia; obesity; synapse

\section{Significance Statement}

Obesity in humans correlates with reduced cognitive function. To investigate the cellular mechanisms underlying this, we used diet-induced obesity in mice and found impaired performance on cognitive tests of hippocampal function. These deficits were accompanied by reduced numbers of dendritic spines, increased microglial activation, and increased synaptic profiles within microglia. Inhibition of microglial activation by transgenic and pharmacological methods prevented cognitive decline and dendritic spine loss in obese mice. Moreover, pharmacological inhibition of the phagocytic activity of microglia was also sufficient to prevent cognitive degradation. This work suggests that microglia may be responsible for obesity-associated cognitive decline and dendritic spine loss.

\section{Introduction}

Obesity is a major global health problem, affecting $\sim 600$ million adults worldwide (World Health Organization, 2017). Obesity

\footnotetext{
Received March 26, 2018; revised July 26, 2018; accepted Aug. 20, 2018.

Author contributions: E.C.C. and E.G. wrote the first draft of the paper; E.C.C., E.A.L., P.K.M., L.B.O., S.M., A.D.Z., N.K. and E.G. edited the paper; E.C.C. and E.G. designed research; E.C.C., E.A.L., P.K.M., L.B.O., S.M., A.D.Z., and N.J.K. performed research; E.C.C., E.A.L.,P.K.M., L.B.O,S.M., A.D.Z., N.J.K., and E.G. analyzed data; E.C.C. and E.G. wrote the paper.

This work was supported by National Institutes of Health, National Institute of Neurological Disorders and Stroke Grant 1R21NS087460-01 to E.G.; and National Institutes of Health Training Fellowship T32MH065214 to E.C.C. We thank Adam T. Brockett, Gary A. Kane, Brandy A. Briones, and Sahana Murthy for helpful comments and advice on the manuscript; Christin Y. Park for help with the ultrastructure imaging and analyses; and Miriam E. Bocarsly for advice on the sucrose studies.

The authors declare no competing financial interests.

*E.A.L. and P.K.M. contributed equally to this study.

Correspondence should be addressed to Dr. Elizabeth Gould, Princeton Neuroscience Institute, Department of

Psychology, Princeton University, Princeton, NJ 08540. E-mail: goulde@princeton.edu.
}

increases the risk of several medical conditions, including diabetes, cardiovascular disease, stroke, and certain cancers (Malnick and Knober, 2006). Despite being less commonly known, a growing body of literature has linked obesity with deficits in cognition. Even in the absence of other illnesses, such as metabolic syndrome or diabetes, obesity diminishes cognitive function on a variety of measures throughout life (Cournot et al., 2006; Gunstad et al., 2007; Li et al., 2008; Smith et al., 2011). Moreover, obesity is a risk factor for developing cognitive disorders later in life, such as dementia and Alzheimer's disease (Beydoun et al., 2008; Profenno et al., 2010). Neuroimaging studies have revealed that obese humans have reduced brain volume (Ward et al., 2005), particularly in brain regions supporting cognition, including the hippocampus (Raji et al., 2010). 
Obesity has been characterized as a condition of chronic inflammation. Systemic inflammation arises from infiltration and activation of macrophages in adipose tissue, leading to increased levels of inflammatory markers in serum and organs, such as liver, pancreas, and brain (Schmidt et al., 2015; Saltiel and Olefsky, 2017). In the hypothalamus of obese rodents, microglia, the macrophages of the brain, respond to these signals by accumulating and releasing cytokines that modulate consumptive behavior (Thaler et al., 2012; Valdearcos et al., 2014). In addition to the production and release of inflammatory mediators, which are known to alter neurons, microglia respond to damage and disease by engulfing neuronal debris (Neumann et al., 2009). Evidence also suggests that microglia play important roles in the healthy brain. For instance, throughout normal brain development, microglia shape neural circuits by engulfing weak synapses (Paolicelli et al., 2011; Schafer et al., 2012).

Some reports suggest a relationship between obesity-induced cognitive decline and microglia. Early-stage obesity in rats produces cognitive deficits along with synapse loss and changes in microglial morphology in the medial prefrontal cortex, a brain region important for cognitive flexibility (Bocarsly et al., 2015). Additional studies have shown that obesity in mice impairs performance on cognitive tasks that require the hippocampus (Hwang et al., 2010; Heyward et al., 2012; Valladolid-Acebes et al., 2013; Hao et al., 2016), increases microglial activation, and that microglia isolated from obese mice are capable of internalizing synaptosomes at a higher rate than controls (Hao et al., 2016). Given what is known about the function of microglia in clearing neuronal debris, one interpretation is that obesity might first destroy synapses, which leads to their subsequent elimination by microglia. However, an alternative interpretation is that obesity renders microglia pathologically reactive, which causes them to engulf otherwise functional synapses. In other words, microglia may play a causal role in obesity-induced synapse loss and cognitive decline. To date, however, no studies have directly addressed this possibility.

We investigated whether microglia are actively involved in obesity-induced cognitive decline by elimination of otherwise functional synapses. Using mouse models of high-fat diet (HFD)or high-sucrose diet (HSD)-induced obesity, we verified that obesity in the absence of diabetes or metabolic syndrome impaired cognition. These changes were accompanied by a loss of dendritic spines, increased microglial activation, and increased presence of synaptic profiles within microglia of the hippocampus. Next, we blocked microglial activation by transgenic and pharmacological methods and prevented obesity-induced cognitive deficits and dendritic spine loss. Finally, we showed that blocking the phagocytic activity of microglia, and their engulfment of synapses, was sufficient to prevent obesity-induced cognitive decline. Our findings indicate that, in obesity, microglia play an active role in cognitive decline, most likely by phagocytosis of otherwise functional synapses.

\section{Materials and Methods}

Animal care and dietary manipulations. All animal procedures were approved by Princeton University Institutional Animal Care and Use Committee and were in accordance with the guidelines of the National Research Council's Guide for the Care and Use of Laboratory Animals. Adult male C56BL/6J (IMSR catalog \#JAX:000664, RRID:IMSR_JAX:000664) and CX3crl ${ }^{\text {GFP/GFP }}$ (IMSR catalog \#JAX:005582, RRID:IMSR_JAX:005582) mice were obtained from The Jackson Laboratory. Heterozygous CX3 $\mathrm{cr} 1^{\mathrm{GFP} /-}$ mice were bred by crossing $C x 3 \mathrm{cr} 1^{\text {GFP/GFP }}$ homozygous male mice with C57BL/6J female mice. Partial knockdown $\mathrm{C} \times 3 \mathrm{cr}^{+/-}$mice were used for these studies because the complete knockdown is known to exhibit im- paired cognitive function, absent synaptic plasticity in the hippocampus, and a different metabolic profile when on long-term HFD compared with WT controls (Rogers et al., 2011; Shah et al., 2015). All mice were group housed in Optimice cages on a reverse 12:12 light/dark cycle.

Adult, male mice ( 8 weeks old) were weight-matched and randomly divided into dietary groups. For HFD studies, each group was given ad libitum access to water and either a nutritionally complete, HFD (4.7 $\mathrm{kcal} / \mathrm{g}$; Research Diets, \#12451; 45\% fat, 20\% protein, and 35\% carbohydrate) or standard rodent chow (3.01 kcal/g; LabDiet \#5001, PMI Nutrition International; $10 \%$ fat, $20 \%$ protein, $70 \%$ carbohydrate). For HSD studies, each group was given ad libitum access to standard rodent chow and either water or water containing $34 \%$ sucrose. Twice weekly, fluid intake was measured and bottles were replaced with fresh solutions. For both HFD and HSD studies, individual body weights and cage food intake were measured weekly. Mice continued on assigned diets until day of death. Three mice on the HSD had overlapping body weights with control-fed mice. Over the course of the diet, these mice did not gain excessive weight (more weight gain than control mice) and thus were excluded from behavior testing.

Minocycline. After $\sim 10$ weeks of HFD exposure, mice were given access to either water or water treated with minocycline $(40 \mathrm{mg} / \mathrm{kg}$ per mouse; Gold Biotechnology). Age-matched nonobese male mice were used as controls. Mice were acclimated to water bottles in cages for at least $4 \mathrm{~d}$ before drugs were administered to the water. Minocycline solution was prepared fresh daily, and water bottles were replaced weekly. Fluid intake was measured daily for each cage. Two weeks after beginning minocycline treatment, mice began habituations for object memory testing. Drug treatment was continued until day of death.

Annexin- $V$. After $\sim 11$ weeks of HFD feeding, mice were given intravenous injections of either saline or annexin-V $(200 \mu \mathrm{g} / \mathrm{kg}$ dissolved in $100 \mu \mathrm{l}$ of saline; BioVision). Age-matched nonobese mice were used as controls. Mice were treated once every $3 \mathrm{~d}$ for a total of three tail vein injections per mouse. The day of the last injection, mice began habituations for object memory testing.

Cognitive testing. All behavior testing was completed during the active cycle for mice (dark).

Object location test. The object location test was used to assess hippocampus-dependent cognitive function (Assini et al., 2009; Barker and Warburton, 2011). The testing apparatus was an open-field box $(23 \times 25 \times 25 \mathrm{~cm})$. Throughout habituation and testing, the room lighting remained low and mice were placed in the boxes in the same orientation. The stimuli presented were objects $<8 \mathrm{~cm}$ in height or width and had varying $3 \mathrm{D}$ surfaces for them to explore. Object exploration was defined as directing the nose toward the object at $2 \mathrm{~cm}$. A discrimination ratio (DR) was calculated by the difference in time spent exploring the novel location versus the familiar location divided by the total time spent exploring both the novel and familiar locations. Mice that did not explore both objects during the test phase were removed from statistical analyses.

Before testing, mice were familiarized to the testing arena by placing them in the arena for $5 \mathrm{~min} 2 \times$ per day for $3 \mathrm{~d}$. To give the mice some familiarity to objects before testing, two objects (different from those used on the testing day) were placed in a random orientation in the arena on the last day of the habituation.

After $3 \mathrm{~d}$ of habituation, testing began, which consisted of a familiarization phase and a test phase. Objects were placed alongside one wall of the arena $\sim 6 \mathrm{~cm}$ away from the corners and $10 \mathrm{~cm}$ from each other. During the familiarization phase, mice were exposed to 2 identical objects until their total investigation time for both objects reached $30 \mathrm{~s}$, or until a total of $10 \mathrm{~min}$ had elapsed. The latency to reach these criteria was recorded for each mouse. After the familiarization phase, mice were returned to their home cage for $5 \mathrm{~min}$ and then placed back into the arena for a $2 \mathrm{~min}$ test. For the test phase, mice were exposed to the same objects used in the familiarization phase. One of the objects remained in the same location and orientation, whereas the other was rotated $180^{\circ}$ and moved to the opposite wall such that the objects were diagonal to each other. The test phase was recorded on camera for later scoring. The location of the novel orientation within the arena was counterbalanced for all tests. 
Barnes maze test. Hippocampal spatial learning and memory was assessed using the Barnes maze test (Bach et al., 1995; Fox et al., 1998). The maze consisted of an open circular platform $(91 \mathrm{~cm}$ in diameter) elevated $90 \mathrm{~cm}$ above the floor (ANY-maze). Twenty equally spaced holes $(5 \mathrm{~cm}$ diameter) were located along the perimeter of the maze, and a rectangular escape box was placed under one of the holes. Using spatial-visual clues, mice were trained to find the location of a hidden escape box located under the platform.

To familiarize mice with the testing maze, each mouse was given a single habituation trial in which they were placed in a start box in the center of the maze. After $10 \mathrm{~s}$ had elapsed, the start box was removed and the mouse was allowed to explore the maze for $3 \mathrm{~min}$ in red light. During the habituation day, the hidden escape box was removed from the maze.

On the first day of testing, mice were given a training trial in which they were placed in the start box. After $10 \mathrm{~s}$ had elapsed, the start box was removed and a bright light was activated ( $\sim 600$ lux $)$ to motivate mice to find the hidden escape box. The mouse was then guided to the escape box. Once inside, the light was turned off and the mouse stayed in the escape box for $1 \mathrm{~min}$. After this initial training session, each testing day consisted of 4 trials per day with an intertrial interval of $\sim 15-20 \mathrm{~min}$. In between trials, mice were kept in individual cages and the maze was cleaned with $70 \%$ ethanol. Acquisition training continued for $5 \mathrm{~d}$. For each trial, the mouse was placed into the start box for $10 \mathrm{~s}$, the light was activated, and the mouse had $3 \mathrm{~min}$ to find the escape box. The trial ended when either $3 \mathrm{~min}$ had elapsed or the mouse found the escape box. If the mouse did not find the escape box, it was guided there. As during the training session, once the mouse was inside the escape box, the light was turned off and the mouse stayed in the escape box for $1 \mathrm{~min}$. To ensure that the hidden escape box was not visible to the animal, three decoy boxes were placed throughout the maze. The time and distance to find the escape box were recorded for each mouse for each trial using videotracking software (Biobserve Viewer, RRID:SCR_014337).

Twenty-four hours after the last acquisition trial, each mouse underwent a 90 s probe trial in which the escape box was replaced with a decoy box. The latency of the mouse to reach the location of the previous escape hole was recorded.

Blood glucose measurement. Mice were fasted overnight before blood collection. Blood was collected via submandibular bleed (Golde et al., 2005) and glucose levels were measured using AlphaTRAX glucometer (Abbott) (Ayala et al., 2010).

Abdominal fat analysis. Following perfusions, bilateral body-fat pads from the abdominal regions were collected and weighed for each mouse.

Diolistic labeling. Diolistic labeling of neurons was achieved using a protocol adapted from O'Brien and Lummis (2006). Mice were deeply anesthetized with Euthasol (120 mg/kg, Virbac) and perfused transcardially with $1.5 \%$ PFA in PBS. Following perfusions, brains were extracted and postfixed in $1.5 \%$ PFA for $1.5 \mathrm{~h}$ at $4^{\circ} \mathrm{C}$. Brains were embedded in $1 \%$ agarose in $\mathrm{PBS}$ to maintain tissue integrity throughout diolistic procedure. Unilateral $150-\mu \mathrm{m}$-thick coronal sections were cut using a Vibratome (Leica Biosystems) and were suspended in cold PBS. Tungsten particles coated with the fluorescent carbocyanine dye DiI (SigmaAldrich) were delivered to cells using the Helios Gene Gun System (Bio$\mathrm{Rad})$ at 60 psi helium gas pressure. Sections were resuspended in PBS after ballistic delivery and kept at $4^{\circ} \mathrm{C}$ overnight to allow for sufficient diffusion of DiI. Sections were then postfixed in cold $4 \%$ PFA for $1 \mathrm{~h}$, rinsed with PBS, then counterstained with Hoechst 33342 (1:1000 in PBS, Invitrogen) for $30 \mathrm{~min}$ at $4^{\circ} \mathrm{C}$. Sections were mounted on Superfrost Plus slides (Thermo Fisher Scientific) with Prolong Gold Antifade Reagent (Invitrogen), coverslipped, and allowed to harden overnight at room temperature. Any animals with poor perfusion quality were excluded from the dendritic spine analysis.

DiI-labeled neurons were visualized with a Carl Zeiss LSM 700 confocal laser scanning microscope using a $63 \times$ oil objective with a zoom factor of 2. $z$ stacks $(0.56 \mu \mathrm{m}$ step) were collected from dendritic segments of five pyramidal cells from the hippocampal CA1 region (for apical dendrites) and five granule cells (GCs) from the dentate gyrus (DG) of each animal. Neurons were selected for analysis if they were fully labeled with DiI. For every cell, dendritic segments selected for analysis were as follows: (1) on secondary or tertiary dendrites, (2)>50 $\mu \mathrm{m}$ away from cell body, (3) predominantly in one focal plane, and (4) 10-25 $\mu \mathrm{m}$ long. A minimum of $50 \mu \mathrm{m}$ total of dendritic segments for each cell was analyzed. Spine densities for each neuron were calculated by dividing the total number of spines by the total length of the dendritic segments and the data expressed as the number of spines per $10 \mu \mathrm{m}$ of dendrite.

Immunohistochemistry. Mice were deeply anesthetized with Euthasol as previously described and transcardially perfused with $4 \%$ PFA in PBS. Brains were then postfixed for $48 \mathrm{~h}$ in $4 \%$ PFA followed by cryoprotection with sucrose for $48 \mathrm{~h}$. Unilateral 40 - $\mu \mathrm{m}$-thick coronal sections embedded in OCT were cut using a Cryostat (Leica Biosystems). Tissue from animals with poor perfusion quality did not undergo histological processing. Tissue sections were washed with either a TBS or PBS buffer, blocked with $5 \%$ donkey serum, and permeabilized with either $0.1 \%$ Triton X-100 or $0.5 \%$ Tween 20 in buffer for $1 \mathrm{~h}$ at room temperature. Primary antibodies were then added for $24 \mathrm{~h}$ at a dilution of 1:500 for rabbit anti-ibal (Schafer et al., 2012) (Wako catalog \#019-19741, RRID: AB_839504), 1:200 for rat anti-CD68 (Schafer et al., 2012) (Bio-Rad/ AbD Serotec catalog \#MCA1957, RRID:AB_322219), 1:500 for rat antiCD11b (Schafer et al., 2012) (Bio-Rad/AbD Serotec catalog \#MCA711G, RRID:AB_323167), 1:500 for rabbit anti-synaptophysin (Wang et al., 2016) (Sigma-Aldrich catalog \#SAB4502906, RRID:AB_10746692), 1:100 for mouse anti-PSD-95 (Rezaï et al., 2012) (Millipore catalog \#MAB1596, RRID:AB_2092365), 1:500 for rabbit anti-GFAP (Lepousez et al., 2010) (Dako catalog \#Z0334, RRID:AB_10013382), 1:500 for rabbit-S100 (Petrova et al., 2013) (Dako catalog \#Z0311, RRID: AB_10013383), and for $48 \mathrm{~h}$ at 1:200 for goat anti-doublecortin (Snyder et al., 2011) (DCX; Santa Cruz Biotechnology catalog \#sc-8066, RRID: AB_2088494) and incubated at $4^{\circ} \mathrm{C}$. After washing, tissue sections were then incubated with species-specific conjugated secondary antibody for $1.5 \mathrm{~h}$ in the dark as follows: donkey anti-rabbit AlexaFluor-488 (Thermo Fisher Scientific catalog \#R37118, RRID:AB_2556546) for iba1, GFAP, and S100; donkey anti-mouse AlexaFluor-568 (Thermo Fisher Scientific catalog \#A10037, RRID:AB_2534013) for CD68, and donkey anti-goat AlexaFluor-568 (Thermo Fisher Scientific catalog \#A-11057, RRID: AB_2534104) for DCX. All secondaries were diluted 1:250 in buffer. Tissue sections were rinsed, mounted onto Suprafrost Plus slides (Thermo Fisher Scientific), dried, and counterstained with Hoechst 33342 (Invitrogen) 1:1000 in water. Slides were then coverslipped using either glycerol in TBS (3:1) or Prolong Gold Antifade Reagent (Invitrogen).

Cell counts. Cell densities for immature neurons (DCX), microglia (ibal or GFP), and astrocytes (GFAP) were analyzed throughout the entire rostrocaudal extent of the dorsal DG (Franklin and Paxinos, 2008) on every sixth section using a BX-60 Olympus microscope assisted by a computer-based system, Stereo Investigator software (MBF Bioscience, RRID:SCR_004314). The reference space (contour) for each brain region (molecular layer $[\mathrm{MOL}]$ of the DG and the stratum radiatum [RAD] of CA1) was delineated by outlining at low power ( $4 \times$ objective); identification of iba1-, GFP-, or GFAP-positive cells was accomplished at high power ( $40 \times$ objective). Identification of DCX was determined using a $100 \times$ oil objective. Cell densities were then determined for each animal by taking the total number of positively labeled cells and dividing it by the volume of the brain region (contour area multiplied by 40 for thickness of cut section). To determine the total volume of the GC layer, the summed contour areas were multiplied by 480 ( 40 for thickness of cut section, 6 for interval between sections, and 2 for bilateral).

Microglial activation analyses. Because microglial activation is a complex process that often affects only a subset of microglial cells in a given brain region ( $\mathrm{Li}$ and Barres, 2018), we used a method adapted from Schafer et al. (2012) that assesses multiple measures of microglial activation (primary process number, cell body area and staining for CD68, a microglial lysosomal marker) to produce a combined overall score per brain region for each mouse. Tissue double-labeled with ibal or GFP and CD68 was analyzed for microglial activation using a confocal microscope (LSM 700, Carl Zeiss). For each animal and brain region, 10 microglial cells (iba1- or GFP-positive) were imaged using a $63 \times$ oil objective in stacks of $0.56-\mu \mathrm{m}$-thick sections. Maximum intensity $z$ projections of the image stacks were created using ImageJ (National Institutes of Health). First, process morphology for each cell was scored in image stacks as 0 ( $\geq 6$ primary processes) or 1 ( $0-5$ primary processes). Second, cell body 
morphology was scored based on quartiles as 0 (cell body area in 2 lower quartile ranges) or 1 (cell body area in 2 upper quartile ranges). Third, the expression pattern of CD68 in each cell was scored. CD68 punctate staining and aggregate staining (defined as staining area $>3 \mu \mathrm{m}^{2}$ ) were counted in the microglial cell body and processes. To account for expansive aggregates, each multiple of $3 \mu \mathrm{m}$ staining area was counted as an additional aggregate. To account for the increased protein expression in the aggregates compared with the punctate stains, the raw counts of aggregate stains were weighted by a factor of 10 and then summed with the punctate counts. The range of all weighted total cell counts was then taken and divided into quartiles. Each quartile was assigned a number from 0 to 3 . An activation score of 0 (least activated) to 5 (most activated) was determined for each microglia cell by summing the morphology scores for process number and cell body area with the CD68 score. Mean activation scores were determined by averaging the activation score for 10 cells per mouse for each brain region.

Microglia and synaptic protein colabeling analyses. Individual microglial cells were analyzed for evidence of internalized synaptic proteins using both a presynaptic (synaptophysin) and postsynaptic (PSD-95) marker. For each animal and brain region, 10 individual microglial cells colabeled with either synaptophysin or PSD-95 were imaged using a confocal microscope (LSM 700, Carl Zeiss) with a $63 \times$ oil objective in stacks of $0.56 \mu \mathrm{m}$ thickness. Imaris software (Bitplane) was used to create $3 \mathrm{D}$ surface renderings of each acquired $z$ stack. Surface rendered images were used to determine the volume of the microglial cell and synaptic protein. Colocalization of the surface rendered microglial cell and synaptic protein was used to determine internalized synaptic protein volume. Percentage of synaptic protein engulfment was determined by dividing the volume of internalized synaptic protein $\left(\mu \mathrm{m}^{3}\right)$ by the volume of the microglial cell $\left(\mu \mathrm{m}^{3}\right)$ (Schafer et al., 2012). For each animal, mean percentage of synaptic protein engulfment was calculated by averaging 10 microglial cells.

Electron microscopy (EM) and ultrastructure analyses. Tissue was prepared for immuno-EM using previously described methods (Tremblay et al., 2010). Mice were deeply anesthetized with Euthasol (see Diolistic labeling) and perfused transcardially with PBS, followed by $3.5 \%$ acrolein, and then 4\% PFA. Following perfusions, brains were extracted and postfixed in $4 \%$ PFA for $2 \mathrm{~h}$ at $4^{\circ} \mathrm{C}$. Brains were embedded in $1 \%$ agarose in PBS and bilateral $50-\mu \mathrm{m}$-thick coronal sections were cut using a Vibratome (Leica Biosystems). Tissue was stored in $-20^{\circ} \mathrm{C}$ in cryoprotectant (30\% ethylene glycol and 30\% glycerol in PBS) until immunolabeling.

For pre-embedding immunoperoxidase labeling, tissue sections (two sections per animal) were washed in PBS and then immersed in $0.1 \%$ sodium borohydride in PBS for $30 \mathrm{~min}$ at room temperature. Rinsed sections were blocked in $0.5 \%$ gelatin and $5 \%$ normal goat serum for $2 \mathrm{~h}$ at room temperature. Rabbit anti-ibal antibody (1:500) was then added for $48 \mathrm{~h}$ at $4^{\circ} \mathrm{C}$. Following PBS washes, sections were incubated for $2 \mathrm{~h}$ at room temperature in goat anti-rabbit IgGs conjugated to biotin (1:500) (Jackson ImmunoResearch Laboratories catalog \#111-066-046, RRID: AB_2337968) followed by streptavidin-HRP (1:500) (Jackson ImmunoResearch Laboratories catalog \#016-030-084, RRID:AB_2337238) for $1 \mathrm{~h}$ at room temperature in blocking solution. Immunolabeling was visualized with DAB (SIGMAFAST DAB tablets; Sigma-Aldrich).

After immunolabeling, sections were processed for EM by immersion in $1 \%$ osmium tetroxide for $1 \mathrm{~h}$ and dehydrated in ascending concentrations of ethanol from $30 \%$ to $100 \%$, including $1 \%$ uranyl acetate in $70 \%$ ethanol for $40 \mathrm{~min}$. Dehydrated sections were immersed in propylene oxide and then impregnated in Durcupan resin and mounted in ACLAR embedding film. Using a binocular microscope, the MOL of the DG was excised and re-embedded onto Durcapan resin blocks. Ultrathin $(65 \mathrm{~nm})$ sections were cut using an ultramicrotome (Leica Microsystems), collected onto copper mesh grids, and examined using a $100 \mathrm{KeV}$ electron microscope (CM100 TEM, Philips).

A total of 100 pictures of ibal-positive processes were taken at $19,000 \times$ in the MOL of the DG for total neuropil area of $\sim 2000 \mu \mathrm{m}^{2}$ per animal. In addition to ibal-positive immunoreactivity, microglial processes were identified by irregular contours that formed obtuse angles, occasional long stretches of endoplasmic reticulum, and membrane- bound inclusions containing cellular profiles that structurally resemble components of synapses, such as postsynaptic densities and presynaptic vesicles. While some cellular material within the membrane-bound inclusion is unidentifiable by ultrastructure, it is often thought to be synaptic material already degraded by microglial lysosomes (Tremblay et al., 2010; Schafer et al., 2012). To quantify microglial phagocytosis, each microglial process was analyzed for the number of membrane-bound inclusions to give a phagocytic index (the number of inclusions per process) (Tremblay et al., 2010; Milior et al., 2016). To avoid variation in inclusion number based on process area size, only similar-sized processes that were clearly identifiable as positive ibal staining were analyzed (process area of $0.1-2.5 \mu \mathrm{m}^{2}$ ). A minimum of 42 processes were analyzed for each animal.

Experimental design and statistical analyses. No statistical methods were used to predetermine sample size; however, sample numbers were chosen based on previous studies with similar types of experiments. Data collection and analyses were performed by an experimenter blind to the experimental group, with the exception of video scoring of cognitive testing in which obese mice were noticeably larger than controls. In such cases, scoring was confirmed by an additional experimenter. Either Prism 6.0 (GraphPad, RRID:SCR_002798) or Rstudio was used for all the statistical analyses and graph preparation. All datasets are expressed as the mean \pm SEM with statistical significance defined as $p<0.05$. The criterion for data point exclusion was defined as $>2$ SDs away from group mean (only one data point was excluded in this study). Body weight data and Barnes maze data were analyzed via a two-way repeatedmeasures ANOVA with Bonferroni post hoc comparisons. Microglia manipulation (transgenic and/or drug) experiments with more than two groups were analyzed with a two-way ANOVA followed by Holm-Sidak post hoc comparisons. All other datasets were analyzed using unpaired two-tailed Student's $t$ tests, with the exception of a small subset of data that did not meet parametric assumptions (as determined by Levene's test) and were not appropriate for log transformation. Those data were analyzed using Mann-Whitney $U$ tests. For each experiment, $n$ sizes, $p$ values, and statistical tests are reported in each figure legend or in Results where applicable.

\section{Results}

\section{HFD induces obesity in adult mice}

We used diet manipulations to induce obesity because the global obesity epidemic is generally believed to be caused by excessive caloric intake (Hill and Peters, 1998; Wang and Liao, 2012). Adult male mice quickly gain weight after ad libitum access to HFD such that, by 2 weeks of feeding, they display significantly increased body weight compared with control-fed mice (Fig. 1A). By the end of a 12 week dietary period, HFD-fed mice were almost $40 \%$ heavier, had a ninefold increase in abdominal fat weights (Fig. 1B), and were visibly larger than controls. Human obesity is defined on the basis of body mass index with the cutoff between healthy and obese at $>20 \%$ weight gain (National Institutes of Health, 2017). Although there is no definitive set of criteria for the designation of obesity in rodents, using the percentage body weight typically used for humans as a measure of obesity, it is reasonable to conclude that our 12 week HFD mice were obese.

Elevated fasting blood glucose is a sign of metabolic syndrome, a precursor to diabetes that frequently co-occurs with obesity. Our obese mice did not have increased fasting blood glucose compared with controls, and these levels fell within the normal range for mice (Fig. 1B) (Ayala et al., 2010). These data indicate that our obese mice had not developed metabolic syndrome during the 12 week diet duration.

\section{Obesity is associated with cognitive impairment}

To test cognitive performance, we used the hippocampusdependent object location (OL) task (Assini et al., 2009; Barker 


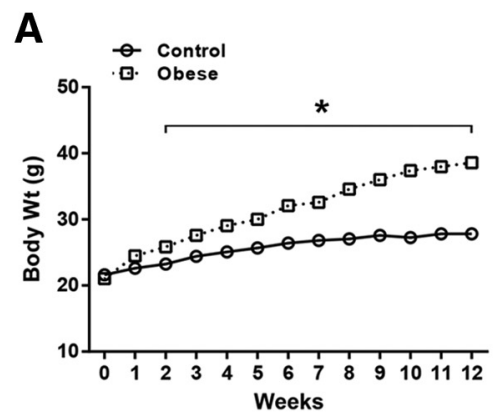

D
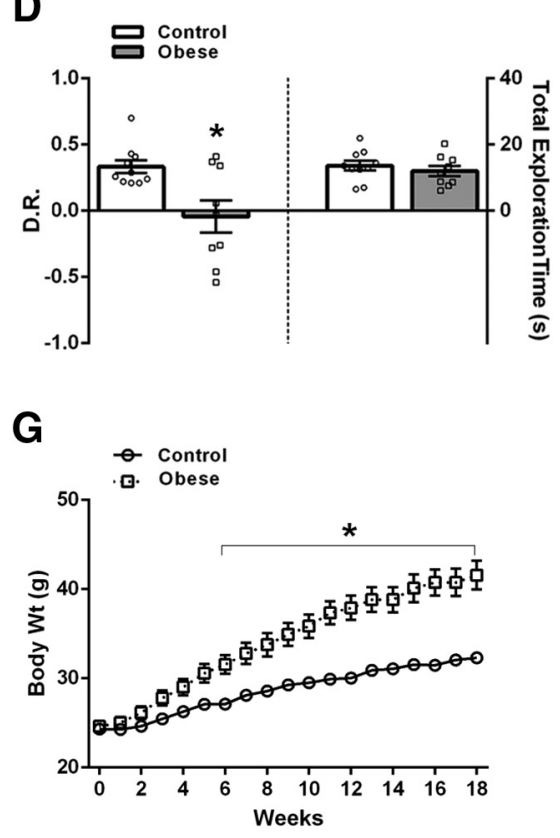

B

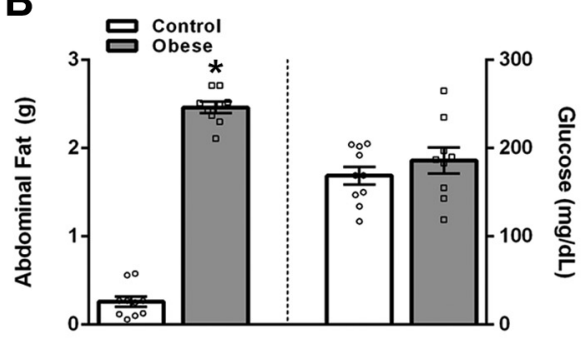

C

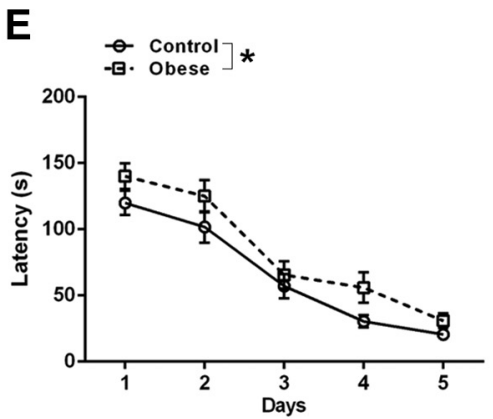

H

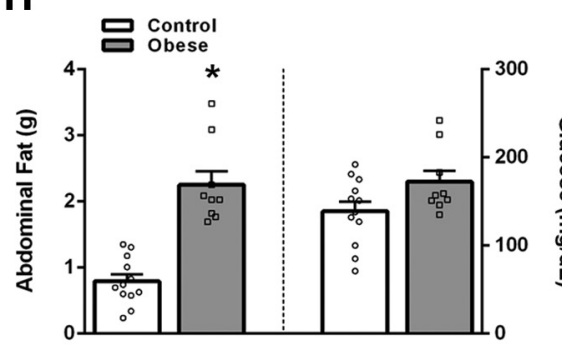

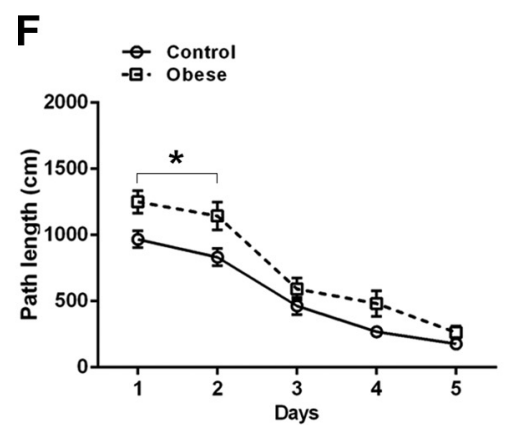

I

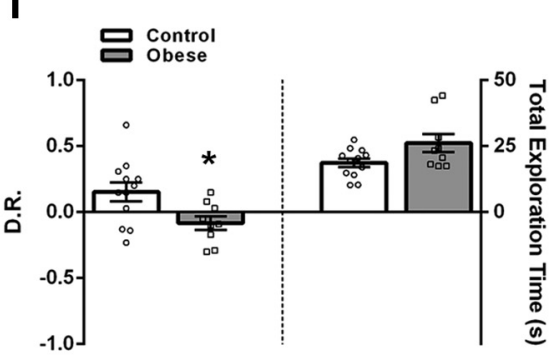

Figure 1. Long-term HFD or HSD feeding-induced obesity impaired performance on hippocampus-dependent cognitive tasks. $A$, Weekly measurements of body weight for control-and HFD-fed mice over 12 weeks (week: $F_{(12,204)}=309.0, p<0.0001$; diet group: $F_{(1,17)}=85.69, p<0.0001$; and week $\times$ diet: $F_{(12,204)}=67.18, p<0.0001$, two-way ANOVA). Bonferroni post hoc comparisons showed differences starting at week $2\left(t_{(17)}=3.52, p=0.0069\right)$. $B$, Left, HFD-fed mice had increased abdominal fat weights at the end of the 12 week HFD $\left(t_{(17)}=25.83, p<0.0001\right.$, unpaired $t$ test). Right, Fasting blood glucose levels were not different between groups $\left(t_{(17)}=0.97, p=0.35\right.$, unpaired $t$ test). $C$, Adapted schematic (Barker and Warburton, 2011) of the hippocampus-dependent OL task. $D$, Left, HFD-induced obese mice had impaired DRs for the $0 \mathrm{~L}$ test $(U=20.50, p=0.046$, Mann-Whitney test). Right, Total time spent exploring the objects during $0 \mathrm{~L}$ testing was not different between groups $\left(t_{(17)}=0.76, p=0.46\right.$, unpaired $t$ test). $E$, There was an overall significant difference between groups in latency $\left(\right.$ day: $F_{(4,88)}=60.27, p<0.0001 ;$ diet group: $F_{(1,22)}=4.81, p=0.039 ;$ and day $\times$ diet group: $F_{(4,88)}=0.44, p=0.78$, two-way ANOVA) and $(\boldsymbol{F})$ path length (day: $F_{(4,88)}=64.77, p<0.0001 ;$ diet group: $F_{(1,22)}=14.24, p=0.0010$; and day $\times$ diet group: $F_{(4,88)}=1.01, p=0.41$, two-way ANOVA) to find the hidden escape box in the Barnes maze test. Bonferroni post hoc comparisons of path length show differences between control and obese on day $1\left(t_{(22)}=2.79, p=0.031\right)$ and day $2\left(t_{(22)}=3.06, p=0.014\right) . G$, Weekly measurements of body weight for control-and HSD-fed mice over 18 weeks (week: $F_{(18,342)}=$ $368, p<0.0001$; diet group: $F_{(1,19)}=24.84, p<0.0001$; and week $\times$ diet group: $F_{(19,342)}=46.26, p<0.0001$, two-way ANOVA $)$ showed differences starting at week $6\left(t_{(19)}=3.76, p=0.0037\right)$. $H$, Left, HSD-fed mice had increased abdominal fat weights at the end of the 18 week dietary period ( $t_{(19)}=6.81, p<0.0001$, unpaired $t$ test). Right, Fasting blood glucose levels for control and HSD-induced obese mice were not different $\left(t_{(19)}=2.00, p=0.060\right.$, unpaired $t$ test). $I$, Left, HSD-induced obesity impaired DRs for the $0 \mathrm{~L}$ cognitive test $\left(t_{(19)}=2.49, p=0.022\right.$, unpaired $t$ test). Right, Total time spent exploring the objects during $0 \mathrm{~L}$ testing was not different between groups $\left(t_{(19)}=1.09, p=0.29\right.$, unpaired $t$ tests). $A-D, n=10$ for control and $n=9$ for HFD-induced obese. $\boldsymbol{E}, \boldsymbol{F}, n=12$ for each group. $\mathbf{G}-\mathbf{I}, n=12$ for control and $n=9$ for HSD-induced obese. Error bars indicate SEM. ${ }^{*} p<0.05$ compared with control.

and Warburton, 2011) (Fig. 1C). In the OL task, obese mice had impaired performance compared with normal weight controls, as measured by lower DRs (Fig. 1D). The low DRs of the obese mice were not due to the fact that they were uninterested in the objects because both groups had similar exploration times with the objects during the test phases (Fig. 1D) and similar latencies to explore the objects during the familiarization phase (control: $210 \pm 37$ s, obese: $171 \pm 28 \mathrm{~s}, t_{(17)}=0.82, p=0.42$, unpaired $t$ test).

As an additional measure of hippocampal function, we examined spatial learning and memory using the Barnes maze test (Bach et al., 1995; Fox et al., 1998). In this task, mice learn the location of a hidden escape box based on spatial-visual cues. There was a difference between control and obese mice in the overall latency (Fig. 1E) and path lengths to find the hidden es- cape box (Fig. 1F). Obese mice had longer path lengths on days 1 and 2 of spatial testing. After spatial learning, the probe test showed that, after sufficient training, obese mice learned the test and were able to perform as well as controls (control: $11.4 \pm 2.5 \mathrm{~s}$, obese: $9.4 \pm 1.6 \mathrm{~s}, t_{(22)}=0.67, p=0.51$, unpaired $t$ test).

To further explore the possibility that our results are due to the fact that mice are obese, and not a result of HFD-induced obesity specifically, we used an additional model of diet-induced obesity to examine cognitive behavior. In addition to standard rodent chow, we provided mice with ad libitum access to water containing 34\% sucrose. Consistent with previous reports (Glendinning et al., 2010), mice fed HSD gained weight and by 6 weeks were significantly heavier than controls (Fig. 1G). Because body weight gain appeared to be slightly slower in HSD-fed mice compared with HFD-fed mice, mice continued on the HSD for 18 
A

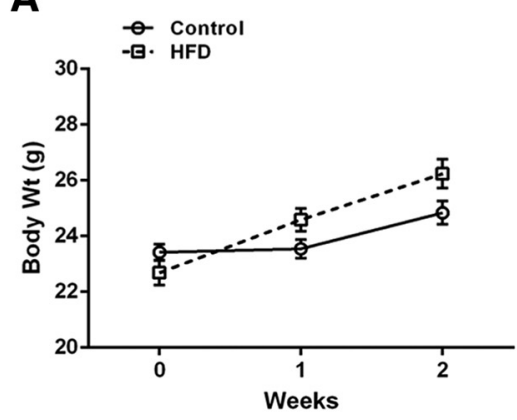

D

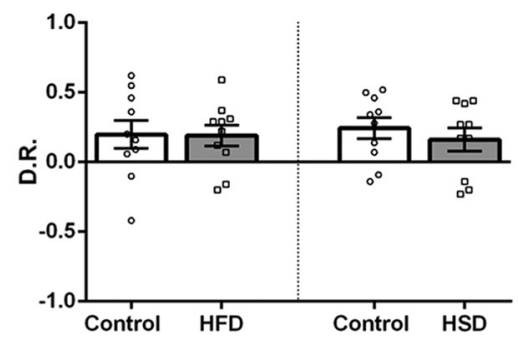

B

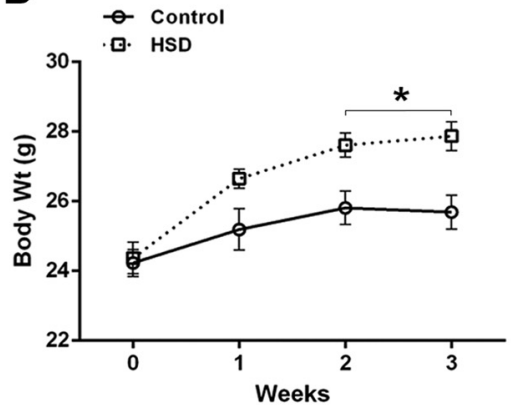

$\mathbf{E}$

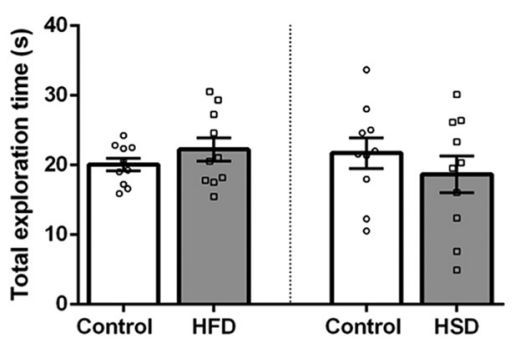

C

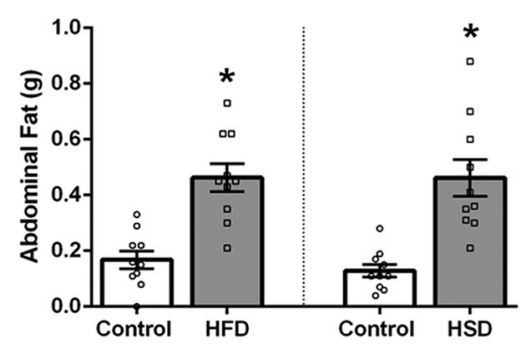

$\mathbf{F}$

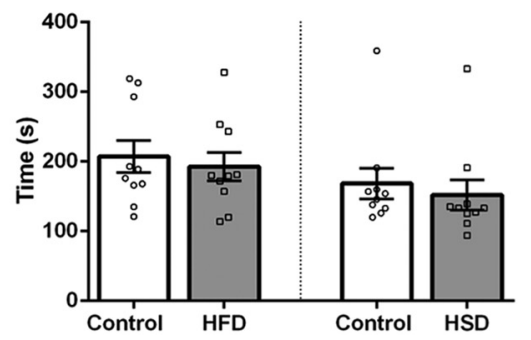

Figure 2. Short-term HFD or HSD feeding does not impair hippocampus-dependent cognition. $A$, Weekly measurements of body weight for control-and HFD-fed mice showed no differences in body weight over 2 weeks (week: $F_{(2,36)}=139.7, p<0.0001$; diet group: $F_{(1,18)}=1.06, p=0.32$; and week $\times$ diet: $F_{(2,36)}=29.08, p<0.0001$, two-way ANOVA). B, Weekly measurements of body weight for control-and HSD-fed mice over 3 weeks (week: $F_{(3,54)}=67.72, p<0.0001$; diet group: $F_{(1,18)}=5.95, p=0.025$; and week $\times$ diet: $F_{(3,54)}=10.02, p<0.0001$, two-way ANOVA) showed differences starting at week $2\left(t_{(18)}=2.90, p=0.020\right)$. C, Left, HFD-fed mice have increased abdominal fat weights at the end of the 2 weeks $\left(t_{(18)}=4.99, p<0.0001\right.$, unpaired $t$ test). Right, HSD-fed mice have increased abdominal fat weights at the end of the 3 week dietary period $\left(t_{(18)}=5.80, p<0.0001\right.$, log transformation followed by unpaired $t$ test). $D$, Left, DRs in the hippocampus-dependent $0 \mathrm{~L}$ test were not different between control and HFD-fed mice $\left(t_{(18)}=0.064, p=0.95\right.$, unpaired $t$ test). Right, DRs in the $0 \mathrm{~L}$ test were not different between control and HSD-fed mice $\left(t_{(18)}=0.74, p=0.47\right.$, unpaired $t$ test $)$. $\boldsymbol{E}$, Left, The total time exploring the objects during the $0 \mathrm{~L}$ test did not differ between control and HFD-fed mice $\left(t_{(18)}=0.97, p=0.34\right.$, log transformation followed by unpaired $t$ test). Right, The total time exploring the objects during the $0 \mathrm{~L}$ test was not different between control and HSD-fed mice $\left(t_{(18)}=0.88, p=0.39\right.$, unpaired $t$ test). $\boldsymbol{F}$, Left, The latency to reach $30 \mathrm{~s}$ total exploration of objects during the familiarization phase of $0 \mathrm{~L}$ was unchanged between control and $\mathrm{HFD}$-fed mice $\left(t_{(18)}=0.47, p=0.64\right.$, unpaired $t$ test). Right, The latency to reach $30 \mathrm{~s}$ total exploration of objects during the familiarization phase of $0 \mathrm{~L}$ was unchanged between control and HSD-fed mice $\left(t_{(18)}=0.53, p=0.60\right.$, unpaired $t$ test $) . A-F$, $n=10$ for each group. Error bars indicate SEM. ${ }^{*} p<0.05$ compared with control.

weeks. By this time, mice in the HSD group were $~ 30 \%$ heavier, visibly larger, and had an approximate threefold increase in abdominal fat weights (Fig. $1 H$ ) compared with controls. Furthermore, blood glucose levels were not different between control or HSD-fed mice (Fig. $1 H$ ).

We next tested whether HSD-induced obesity caused similar deficits in cognitive behavior, as seen with HFD-induced obesity. Object memory testing showed that mice fed the HSD had lower DRs in OL compared with controls (Fig. 1I). DRs were comparable between obese mice induced by either HFD or by HSD. Control and HSD-induced obese mice spent similar amounts of time exploring the objects during the test phase (Fig. 1I) and had similar latencies to explore the objects during the familiarization phase (control: $199 \pm 19$ s, obese: $159 \pm 25 \mathrm{~s}, t_{(19)}=1.32, p=$ 0.20 , unpaired $t$ test).

We also tested whether exposure to a short-term HFD or HSD would cause similar cognitive impairments. We examined cognitive behavior before the emergence of obesity from either HFD or HSD feeding. Mice fed HFD for 2 weeks did not show increases in body weight compared with controls (Fig. 2A), whereas mice fed HSD were statistically heavier than control mice at 3 weeks (Fig. $2 B)$. While both HFD-fed and HSD-fed mice had increases in abdominal fat weights (Fig. 2C), fat accumulation was dramatically less than that of mice that had been fed the HFD for 12 weeks or HSD for 18 weeks (compare with Fig. $1 B$ and Fig. $1 H$, respectively). Examination of cognitive behavior in OL showed that mice exposed to HFD short-term performed as well as controls (Fig. 2D). There were no differences found in measures of object exploration during the test phase (Fig. 2E) or familiarization phase (Fig. 2F). Similarly, mice exposed to a short duration of HSD had similar DRs in OL as control mice (Fig. 2D) and were not different in measures of object exploration during the test phase (Fig. 2E) or familiarization phase (Fig. 2F). Together, our results suggest that long-term ad libitum feeding of either type of high-calorie diet (HFD or HSD) produces obesity and cognitive impairment. We thus continued with the following experiments using HFD-induced obesity.

\section{Obesity is associated with decreased dendritic spine density}

Because dendritic spines, the primary sites of excitatory synapses, have been linked to synaptic plasticity and cognition (Yuste and Bonhoeffer, 2001; Yuste, 2011), we hypothesized that they might be altered by obesity. Using DiI labeling, we examined dendritic spine density in two neuronal populations of the dorsal hippocampus: the GCs of the DG and the pyramidal cells of the CA1 region. Obesity decreased dendritic spine density on both of these cell populations. Compared with controls, obese mice had fewer dendritic spines on GC dendrites (Fig. $3 A, C$ ) as well as on apical dendrites of CA1 pyramidal cells (Fig. $3 B, C$ ).

\section{Obesity does not alter the number of new neurons}

The DG is known to continuously give rise to new neurons throughout adulthood (Snyder and Cameron, 2012; Jessberger and Gage, 2014). Given that impaired cognition has been linked to reductions in the number of new neurons (Opendak and Gould, 2015), we investigated the effects of obesity on adult neurogenesis in the DG. Examination of immature neuronal marker 
A

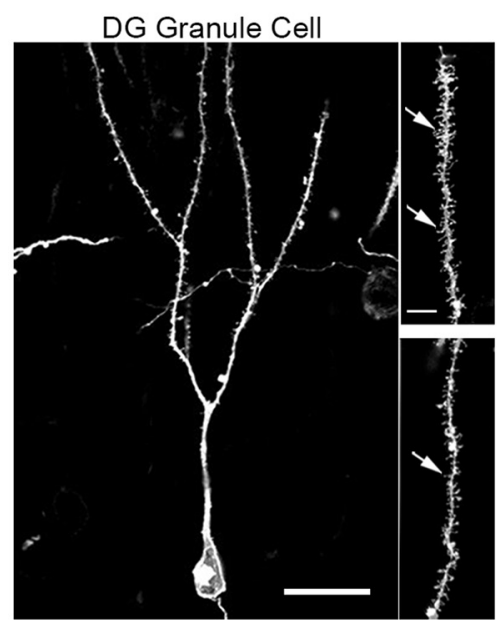

D

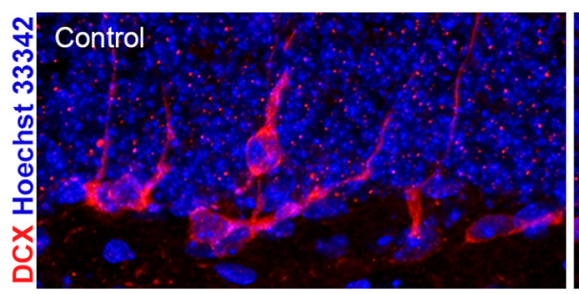

B

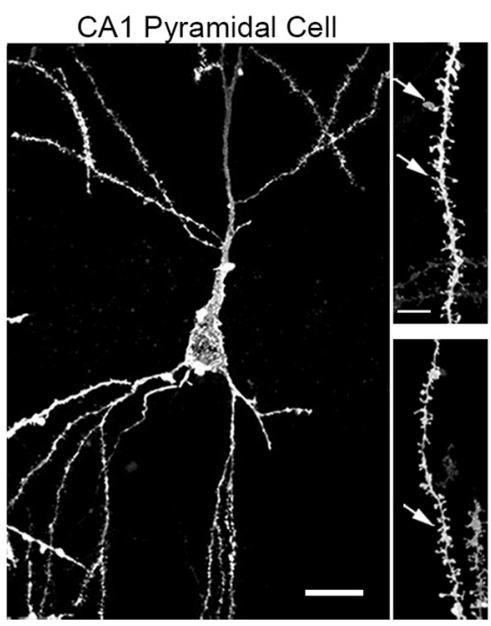

C

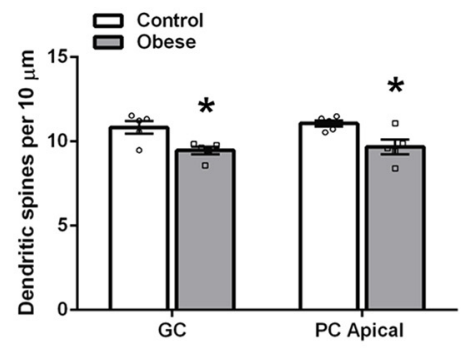

Figure 3. Obesity is associated with decreased dendritic spine density, but not changes in the number of immature neurons in the hippocampus. $\boldsymbol{A}$, Dil-labeled GC from the DG. $\boldsymbol{B}$, Dil-labeled pyramidal cell from the CA1 region of the hippocampus with magnified views of dendritic segments showing dendritic spines (arrows) from control (top) and obese (bottom) mice. Scale bars: low magnification, $20 \mu \mathrm{m}$; high magnification, $5 \mu \mathrm{m}$. C, Spine density of obese mice was lower than controls on dendrites of DG GCs $\left(t_{(8)}=3.12, p=0.014\right)$, as well as on apical dendrites of CA1 pyramidal cells (PC apical) $\left(t_{(8)}=2.98, p=0.018\right)$. D, DCX immunolabeling in the DG of control and obese mice. Scale bar, $20 \mu \mathrm{m}$. $E$, Left, The density of DCX-positive neurons in the dorsal DG for control and obese mice did not differ $\left(t_{(21)}=0.44, p=0.67\right)$. Right, There was no difference in the volume of the dorsal $\mathrm{GC}$ layer $\left(t_{(21)}=1.31, p=0.20\right)$. $\boldsymbol{C}, n=5$ for each group $(5$ cells were averaged per animal with at least $50 \mu \mathrm{m}$ of dendrite analyzed per cell). $\boldsymbol{E}, n=11 \mathrm{for}$ control and $n=12$ for obese. Error bars indicate SEM. ${ }^{*} p<0.05$ (unpaired $t$ test).

DCX revealed that obesity did not decrease the number of new neurons in the dorsal DG (Fig. $3 D, E$ ). There was no difference between groups in the volume of the GC layer (Fig. $3 E$ ).

\section{Obesity is associated with increased activation of microglia but not astrocytes}

Because both microglia and astrocytes are involved in synapse elimination during normal brain development (Paolicelli et al., 2011; Schafer et al., 2012; Chung et al., 2013; Fields et al., 2015) as well as after brain damage in adulthood (Aldskogius et al., 1999; Aguzzi et al., 2013), one possible scenario for dendritic spine loss in the obese brain involves glia. To investigate this, we first examined whether obesity alters microglial activation. We focused our attention to the brain regions where we found dendritic spine loss, namely, the DG MOL and the CA1 RAD. These brain regions contain the dendrites from GCs and CA1 pyramidal cells, respectively. We adapted a previously published rating scale to evaluate microglial activation using microglia morphology and the microglial lysosomal marker CD68 (Schafer et al., 2012). CD68 is often used to assess phagocytic capacity (Ramprasad et al., 1996; Neumann et al., 2009) and has been shown to increase when microglia are engaging in phagocytosis (Schafer et al., 2012). Compared with controls, obese mice had more microglia displaying characteristic features of activation (i.e., decreased primary process number, increased cell body area, increased CD68 labeling) in the MOL (Fig. 4A,C) and RAD (Fig. $4 A, D$ ) of the hippocampus.

Microglia increase in number in response to damage (Nimmerjahn et al., 2005), so we investigated whether microglial cell numbers were affected by obesity. Although obesity caused robust increases in microglial activation, there was no substantial change in microglial number in either of the brain regions examined (Fig. 4B). Furthermore, our changes in microglial activation in the hippocampus were not due to HFD feeding, as short-term HFD exposure did not alter microglial activation (Control: $1.82 \pm 0.23$ activation score, HFD: $2.20 \pm 0.22$ activation score, $t_{(18)}=1.20, p=0.25$, unpaired $t$ test).

The obesity-associated changes in microglia that we observed could be due to obesity causing general increases in glial reactivity. Given that astrocytes also engulf synapses during development (Chung et al., 2013) and after neural damage (Aldskogius et al., 1999), we investigated whether obesity was associated with alterations in astrocyte activation. Because GFAP has been used as an indicator of reactive astrocytes (Pekny and Nilsson, 2005), we examined the number of GFAP-positive astrocytes and did not detect any differences between control and obese mice in the hippocampus (Fig. 5A,B). Using the astrocyte marker S100, examination of astrocyte morphology did not show differences between groups (Fig. $5 C$ ). Thus, it appears that obesity induces notable changes in microglial activation, but no obvious changes in astrocytes in the hippocampus.

\section{Obesity is associated with increased microglial phagocytosis} of synaptic profiles

Since we found increased microglial activation in brain regions of dendritic spine loss, we hypothesized that microglia were phagocytosing synapses in the obese mice. Using $3 \mathrm{D}$ reconstruction and 
A

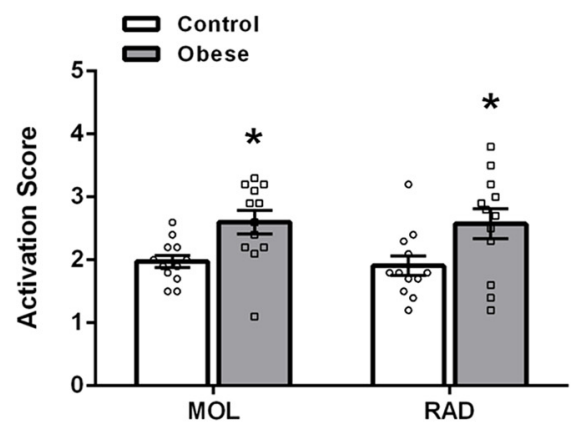

C

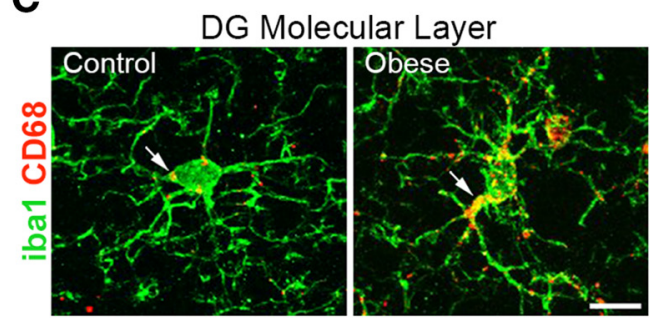

E

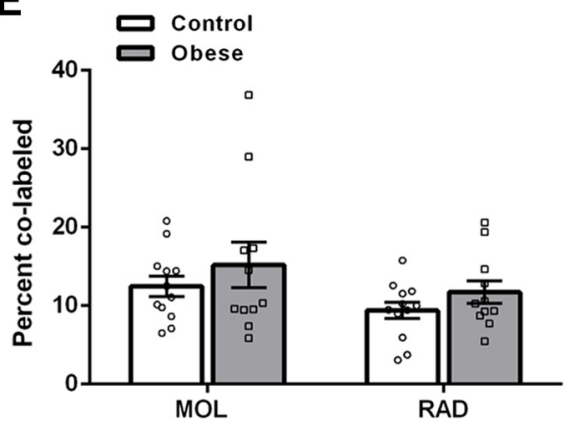

G

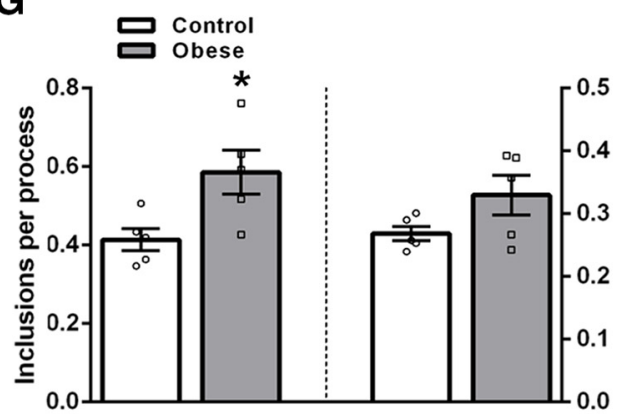

B

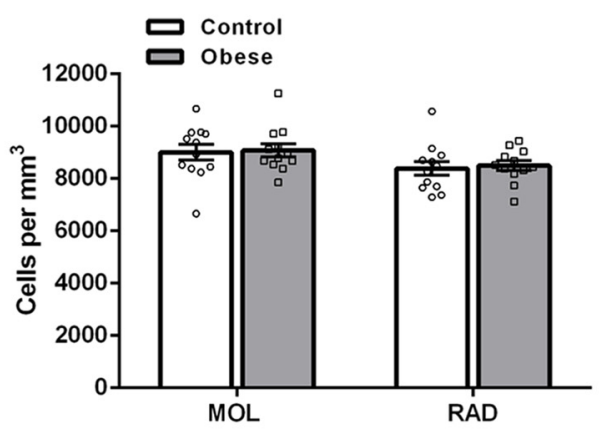

D

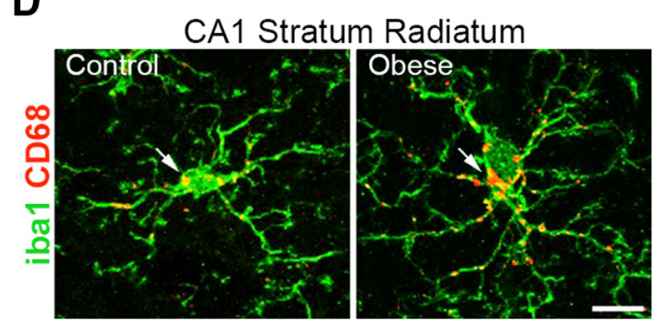

F

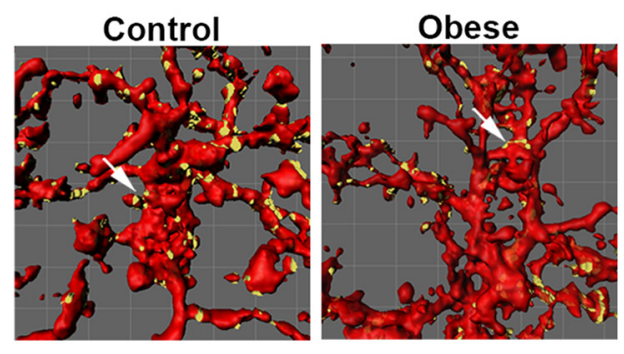

H
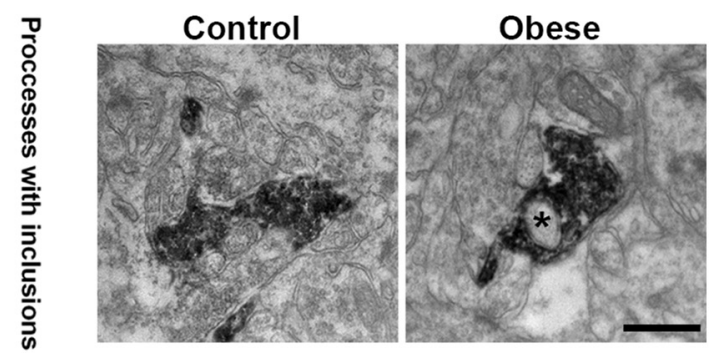

Figure 4. Obesity is associated with increased microglial activation and increased synaptic inclusions in microglial processes. $A$, Microglial activation scores in the MOL of the DG $\left(t_{(22)}=3.00, p=\right.$ $0.0066)$ and RAD of the CA1 region $\left(t_{(22)}=2.56, p=0.028\right)$ were higher in obese mice compared with controls. $N=12$ for each group (10 cells were averaged per animal). $\boldsymbol{B}$, The number of iba1-positive microglia in the MOL $\left(t_{(22)}=0.18, p=0.86\right)$ and $\operatorname{RAD}\left(t_{(22)}=0.34, p=0.74\right)$ did not differ. $N=12$ for each group. MOL $(C)$ and RAD (D) immunolabeled with iba1 (green) and CD68 (red). Scale bar, $10 \mu \mathrm{m}$. Arrows indicate CD68 and iba1 colabeling. $\boldsymbol{E}$, The percentage of colabeling of the presynaptic marker synaptophysin with CD11b-positive microglia in the M0L $\left(t_{(21)}=0.87\right.$, $p=0.39)$ and $\operatorname{RAD}\left(t_{(21)}=1.32, p=0.20\right)$ was not different between groups. $N=12$ for control and $n=11$ for obese (10 cells were averaged per animal). $\boldsymbol{F}$, Surface rendered image of CD11b-positive microglia (red) colabeled with synaptophysin (yellow) from the MOL. Arrows indicate colabeling. G, Left, Ultrastructural analyses of the number of putative synaptic inclusions per iba1-positive process revealed an increase in obese mice compared with controls $\left(t_{(8)}=2.74, p=0.026\right)$. Right, There was no difference between groups in the number of iba1-positive processes with putative synaptic inclusions $\left(t_{(8)}=1.74, p=0.12\right.$, log transformation followed by unpaired $t$ test). $N=5$ for each group with $54-113$ processes averaged for each animal. $\boldsymbol{H}$, EM of a microglial process immunolabeled with iba1 (electron-dense material) from the MOL. Scale bar, $500 \mathrm{~nm}$. ${ }^{*}$ Membrane-bound inclusion within a microglial process. Error bars indicate SEM. ${ }^{*} p<0.05$ (unpaired $t$ test).

surface rendering of microglia and synaptic proteins, we examined the percentage of synaptic proteins colocalized with microglial cells. Examination of the percentage of synaptophysin colabeled with CD11b-positive microglia did not reveal differences between control and obese mice in the MOL or RAD of the hippocampus (Fig. 4E, F). Similarly, examination of PSD-95 colabeled with ibal-positive microglia did not show differences between groups in the MOL (control: $2.84 \pm 1.13 \%$, obese: $2.14 \pm$ $0.71 \%, t_{(18)}=0.47, p=0.65$, unpaired $t$ test). Because it is possible that microglia rapidly degrade synaptic proteins after phagocy- 
A

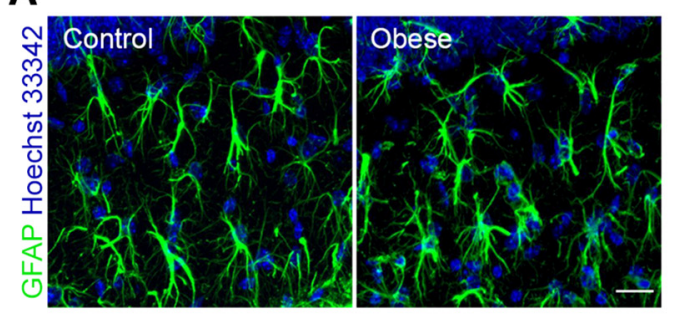

B

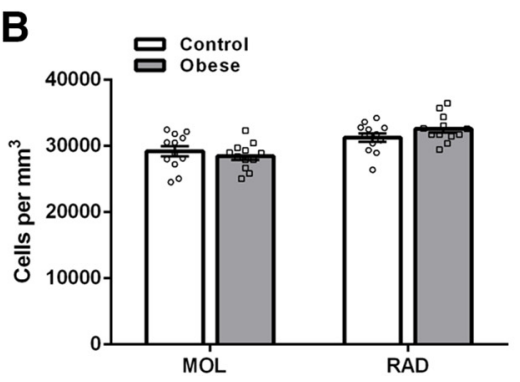

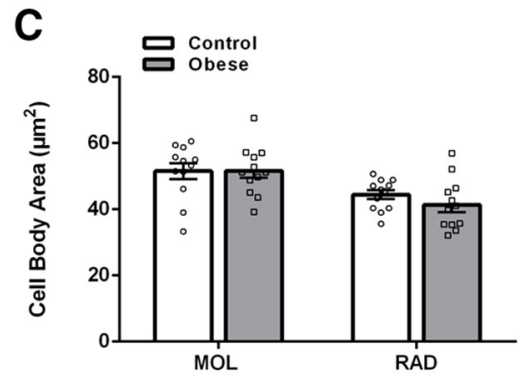

Figure 5. Obesity does not alter astrocyte density or size. $A$, Image from MOL of the hippocampus immunolabeled with astrocyte-marker GFAP (green) and counterstained with Hoechst 33342 (blue). Scale bar, $20 \mu \mathrm{m}$. $\boldsymbol{B}$, The number of GFAP-positive cells was not different in the MOL of the DG $\left(t_{(22)}=0.78, p=0.44\right)$ or RAD of the CA1 region $\left(t_{(22)}=1.52, p=0.14\right)$ between groups. C, Cross-sectional cell body area of S100-positive astrocytes was not changed in the $\mathrm{MOL}\left(t_{(22)}=0.017, p=0.99\right)$ or $\operatorname{RAD}\left(t_{(22)}=1.18, p=0.25\right)$. A, B, $n=12$ for each group.,$n=12$ for each group (10 cells were averaged per animal). Error bars indicate SEM. ${ }^{*} p<0.05$ (unpaired $t$ test).

tosis, we examined microglial phagocytosis using immuno-EM. Ultrastructural analyses of membrane-bound inclusions, which are thought to represent components of synapses (Tremblay et al., 2010; Schafer et al., 2012), within iba1-positive microglial processes, revealed that obesity coincides with increased numbers of inclusions per microglial process (Fig. 4G,H).

\section{HFD induces obesity in Cx3cr1-deficient mice}

The chemokine fractalkine is expressed in the hippocampus where it binds to receptors located exclusively on microglia. Once activated, the fractalkine receptor $(\mathrm{Cx} 3 \mathrm{cr} 1)$ has been shown to increase microglial motility and activation. To further examine the role of microglia in obesity-induced cognitive decline, we used transgenic $C \times 3 \mathrm{cr} 1^{+/-}$mice, in which one allele of $C \times 3 \mathrm{cr} 1$ is replaced with the gene for GFP (Jung et al., 2000). We decided to use heterozygous $\mathrm{C} \times 3 \mathrm{Crl}^{+/-}$instead of homozygous $\mathrm{C} \times 3 \mathrm{Cr}^{-/-}$mice because greater abnormalities in hippocampal structure and cognitive behavior have been observed with the complete knock-out (Rogers et al., 2011; Xiao et al., 2015; Sellner et al., 2016). Consistent with what we observed for WT mice, adult $\mathrm{C} \times 3 \mathrm{crl}^{+/-}$ mice fed HFD for 12 weeks were significantly heavier than control-fed $C \times 3 \mathrm{crl}^{+/-}$mice (Fig. $6 A$ ). There was also more than a 13-fold increase in abdominal fat weights in the HFD-fed $\mathrm{C} \times 3 \mathrm{crl}^{+/-}$mice compared with control-fed $\mathrm{C} \times 3 \mathrm{crl}^{+/-}$mice $\left(\mathrm{C} \times 3 \mathrm{crl}^{+/-}\right.$control: $0.19 \pm 0.05 \mathrm{~g}, \mathrm{C} \times 3 \mathrm{cr} 1^{+/-}$obese: $2.62 \pm$ $0.12 \mathrm{~g}, U=0, p<0.0001$, Mann-Whitney test).

\section{Partial knockdown of $\mathrm{Cx} 3 \mathrm{cr} 1$ prevents obesity-associated cognitive decline and microglial activation}

After 12 weeks of HFD, we examined performance on the OL test. Obese $\mathrm{Cx} 3 \mathrm{crl}^{+/-}$mice performed as well as control-fed $\mathrm{C} \times 3 \mathrm{crl}^{+/-}$mice in the OL test (Fig. 6B). There was no difference between groups in the total time spent exploring the objects during the test phase (Fig. $6 \mathrm{~B}$ ) or in the latency to explore objects during the familiarization phase $\left(\mathrm{C} \times 3 \mathrm{cr} 1^{+/-}\right.$control: $303 \pm 45 \mathrm{~s}$, $C \times 3 \mathrm{cr}^{+/-}$obese: $216 \pm 22 \mathrm{~s}, t_{(21)}=1.78, p=0.090$, unpaired $t$ test). Both control and obese transgenic mice had positive DRs that were similar to WT controls, suggesting that the lack of difference between groups is not attributable to reduced levels of $\mathrm{Cx} 3 \mathrm{cr} 1$ impairing their ability to perform OL.

Examination of microglial activation scores in the hippocampus of WT and transgenic mice revealed that partial knockdown of $\mathrm{Cx} 3 \mathrm{cr} 1$ dampens microglial activation in nonobese control mice. Furthermore, reduced $\mathrm{Cx} 3 \mathrm{cr} 1$ prevented obesity-induced increases in microglial activation such that there was no difference in the mean activation scores of GFP-positive microglia between control and obese $C \times 3 \mathrm{crl}^{+/-}$mice in the MOL (Fig. 6C,E) or RAD (Fig. $6 D, F$ ) of the hippocampus. Obesity did not affect the number of microglia in $C \times 3 \mathrm{crl}^{+/-}$transgenic mice (MOL, $\mathrm{C} \times 3 \mathrm{crl}^{+/-}$control: $8677 \pm 157$ cells per $\mathrm{mm}^{3}, \mathrm{C} \times 3 \mathrm{crl}^{+/-}$obese: $8826 \pm 160$ cells per $\mathrm{mm}^{3}, t_{(22)}=0.66, p=0.52$; RAD, $C \times 3 \mathrm{cr} 1^{+/-}$ control: $8259 \pm 214$ cells per $\mathrm{mm}^{3}, \mathrm{Cx} 3 \mathrm{crl}^{+/-}$obese: $8279 \pm 155$ cells per $\mathrm{mm}^{3}, t_{(22)}=0.07, p=0.94$; unpaired $t$ tests).

\section{Minocycline treatment prevents obesity-associated cognitive decline and microglial activation}

We next investigated whether a drug known to dampen microglial activation would prevent obesity-associated cognitive decline and dendritic spine loss. The antibiotic minocycline readily crosses the blood-brain barrier and has been used to pharmacologically inhibit microglial activation in animal models of neuroinflammation and CNS injury (Tikka et al., 2001; Plane et al., 2010; Kobayashi et al., 2013). We treated obese mice with minocycline in the drinking water for 2 weeks after 10 weeks of HFD. This treatment regimen of minocycline had no effect on body weight (Fig. 7A) or abdominal fat weights (obese: $1.85 \pm 035 \mathrm{~g}$, obese + minocycline: $1.50 \pm 0.22 \mathrm{~g}, t_{(18)}=0.85, p=0.41$, unpaired $t$ test), both of which remained high due to HFD feeding.

Consistent with previous reports (Schafer et al., 2012; Kobayashi et al., 2013; Shigemoto-Mogami et al., 2014; Zhao et al., 2015), we found that minocycline diminished microglial activation. Minocycline-treated obese mice showed decreased mean activation scores of iba1-positive microglia in the MOL and RAD of the hippocampus (Fig. $7 B, C, D$ ). There were no substantial differences detected in microglial cell number (MOL, obese + vehicle: $7482 \pm 253$ cells per $\mathrm{mm}^{3}$, obese + minocycline: $7536 \pm$ 208 cells per $\mathrm{mm}^{3}, t_{(18)}=0.17, p=0.87$; RAD, obese + vehicle: $7717 \pm 225$ cells per $\mathrm{mm}^{3}$, obese + minocycline: $7456 \pm 184$ cells per $\mathrm{mm}^{3}, t_{(18)}=0.90, p=0.38$; unpaired $t$ tests).

Because minocycline has additional actions other than to dampen microglial activation under conditions of inflammation (Orsucci et al., 2009; Plane et al., 2010; Shultz and Zhong, 2017), we next tested whether minocycline alters cognitive performance in both control and obese mice. Two weeks of minocycline treatment in nonobese controls had no effect on body weight (control + vehicle: $29.5 \pm 0.68 \mathrm{~g}$, control + minocycline: $30.0 \pm 0.85$, week: $F_{(3,54)}=13.37, p<0.0001$, treatment group: $F_{(1,18)}=$ $0.0054, p=0.94$, and week $\times$ treatment: $F_{(3,54)}=0.80, p=0.50$, two-way ANOVA) or on abdominal fat weights (control + vehicle: $0.51 \pm 0.16 \mathrm{~g}$, control + minocycline: $0.32 \pm 0.06 \mathrm{~g}, t_{(18)}=$ $1.10, p=0.29$, unpaired $t$ test). Consistent with our previous findings, obesity impaired cognitive function such that untreated obese mice had lower DRs on the OL test compared with untreated nonobese control mice (Fig. 7E). Obese mice treated with 
A

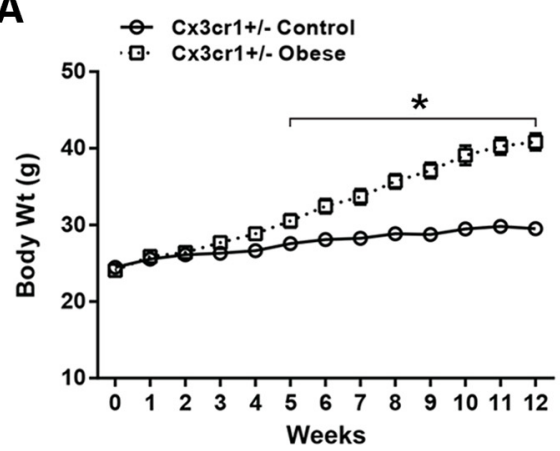

C

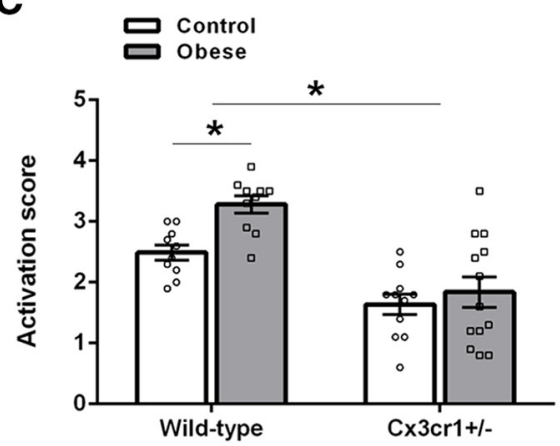

E

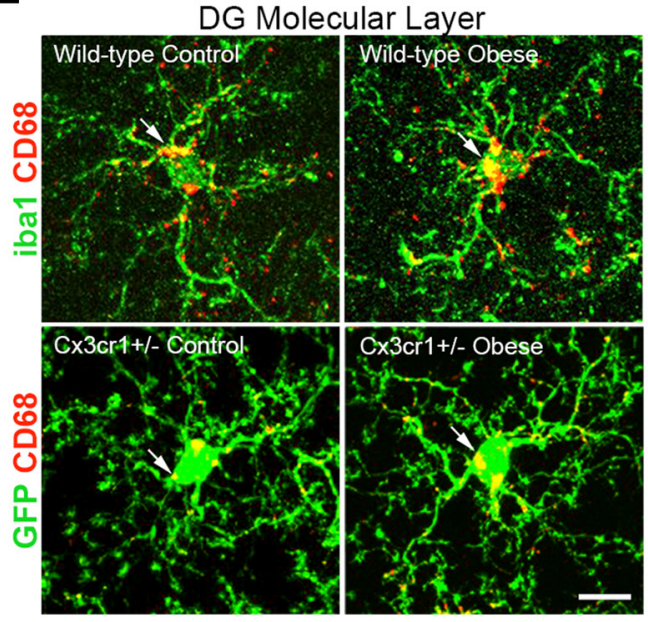

B

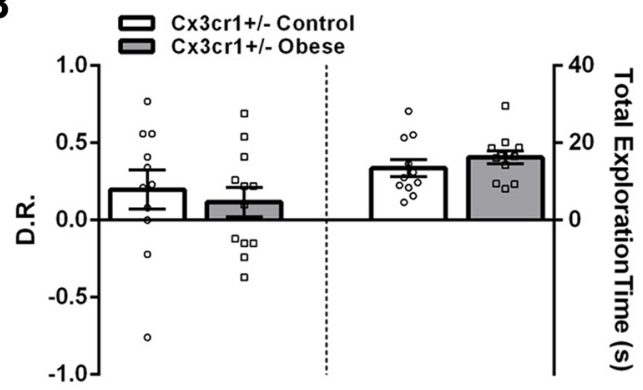

D

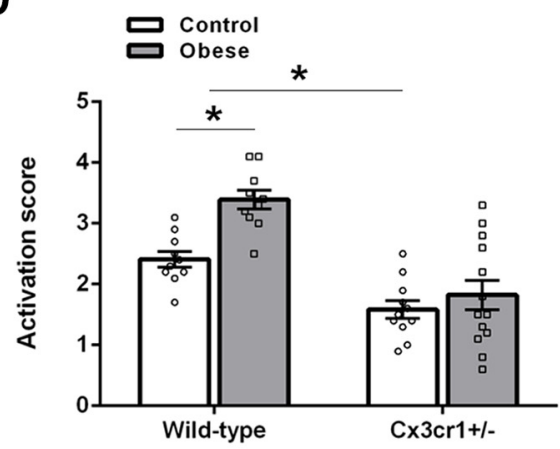

$\mathbf{F}$

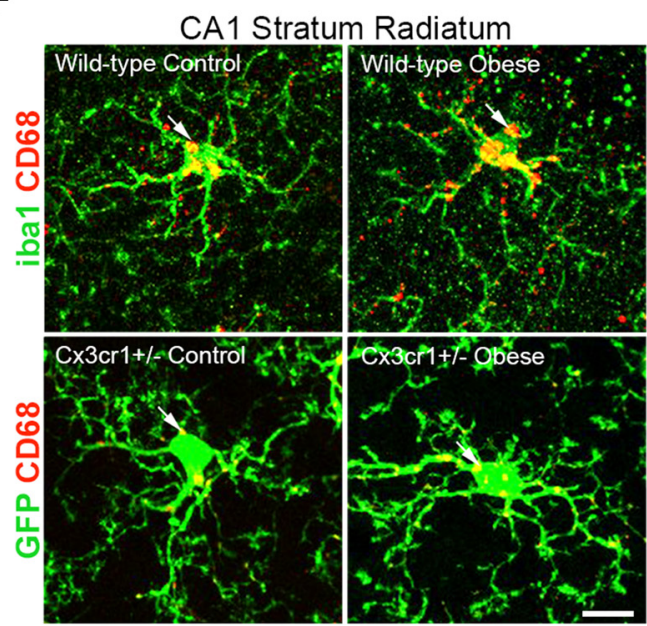

Figure 6. Obesity does not produce cognitive decline or microglial activation in mice with partial knockdown of $\mathrm{Cx} 3 \mathrm{cr} 1$. $\boldsymbol{A}$, Weekly measurements of body weight for control- and HFD-fed $\mathrm{CX}_{\mathrm{C} C 1^{+/-}}$mice over 12 weeks (week: $F_{(12,276)}=321.2,<0.0001$; diet group: $F_{(1,23)}=31.09, p<0.0001$; and week $\times$ diet: $F_{(12,276)}=98.84, p<0.0001$, two-way ANOVA) showed significant increases starting at week $5\left(t_{(23)}=3.10, p=0.027\right)$. B , Left, DRs in the hippocampus-dependent $0 \mathrm{~L}$ test were unchanged $\left(t_{(21)}=0.51, p=0.62\right.$, unpaired $t$ test $)$. Right, The total time exploring the objects during the $0 \mathrm{~L}$ test was not different $\left(t_{(21)}=1.00, p=0.33\right.$, unpaired $t$ test). $C, C \times 3$ cr1 deficiency reduces microglial activation in the MOL of the DG (diet group: $F_{(1,40)}=6.75, p=0.013$; genotype group: $F_{(1,40)}=36.12, p<0.0001$; and diet $\times$ genotype: $F_{(1,40)}=2.37, p=0.13$, two-way ANOVA). Holm-Sidak post hoc comparisons show an increase in microglial activation scores in the MOL in WT obese mice compared with WT control $\left(t_{(40)}=2.81, p=0.023\right)$, and reduced microglia activation scores in the MOL of transgenic $C \times 3 \mathrm{cr} 1^{-/-}$control and obese mice compared with WT control and obese mice (WT control vs $C \times 3 c r 1^{-1-}$ control: $t_{(40)}=3.10, p=0.014$; WT control vs $C \times 3 c r 1^{-1-}$ obese: $t_{(40)}=2.46, p=0.036$; WT obese vs $C \times 3 c r 1^{-/-}$control: $t_{(40)}=5.97$,

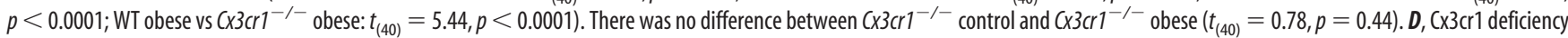
reduces obesity-induced microglial activation in the $R A D$ of the $C A 1$ region (diet group: $F_{(1,40)}=10.67, p=0.0022$; genotype group: $F_{(1,40)}=41.05, p<0.0001$; and diet $\times$ genotype: $F_{(1,40)}=$ $3.91, p=0.055$, two-way ANOVA). Holm-Sidak post hoc comparisons show an increase in microglial activation scores in the RAD in WT obese mice compared with WT control $\left(t_{(40)}=3.56, p=\right.$ 0.0039), and reduced microglial activation scores in the RAD of transgenic mice compared with WT control and obese mice (WT control vs $C \times 3 c r 1^{-/-}$control: $t_{(40)}=3.08, p=0.011 ;$ WT control vs $\left(x 3 \mathrm{Cr}^{-1-}\right.$ obese: $t_{(40)}=2.26, p=0.057$; WT obese vs $\left(x 3 \mathrm{cr} 1^{-1-}\right.$ control: $t_{(40)}=6.71, p<0.0001$; WT obese vs $\left(x 3 \mathrm{cr} 1^{-1-}\right.$ obese: $\left.t_{(40)}=6.04, p<0.0001\right)$. There was no difference between $\mathrm{C} \times 3 \mathrm{Cr}^{-1-}$ control and $\mathrm{C} \times 3 \mathrm{Cr}^{-1-}$ obese $\left(t_{(40)}=0.96, p=0.35\right)$. Images of iba1-positive (green, top row) or GFP-positive microglia (green, bottom row) immunolabeled with CD68 (red) from WT

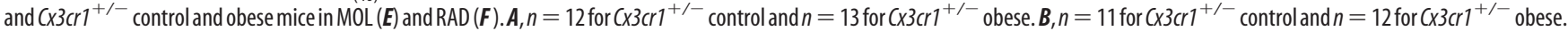
$C-F, N=10$ for WT control and obese, $n=11$ for $C \times 3 \mathrm{Cr}^{+/-}$control, and $n=13$ for $C \times 3 \mathrm{Cr}^{+/-}$obese (10 cells were averaged per animal). Scale bar, $10 \mu \mathrm{m}$. Arrows indicate CD68 and iba1 or GFP colabeling. Error bars indicate SEM. ${ }^{*} p<0.05$.

minocycline performed better than untreated obese mice, and their DRs were comparable with that of nonobese control mice, whereas minocycline had no effect on cognitive performance in nonobese control mice. While during the familiarization phase of the OL test, minocycline-treated obese mice had longer latencies to explore the objects (control + vehicle: $111 \pm 9 \mathrm{~s}$, control + minocycline: $120 \pm 20 \mathrm{~s}$, obese + vehicle: $171 \pm 17 \mathrm{~s}$, obese + minocycline: $279 \pm 35$ s, diet group: $F_{(1,38)}=23.28, p<0.0001$, 
A

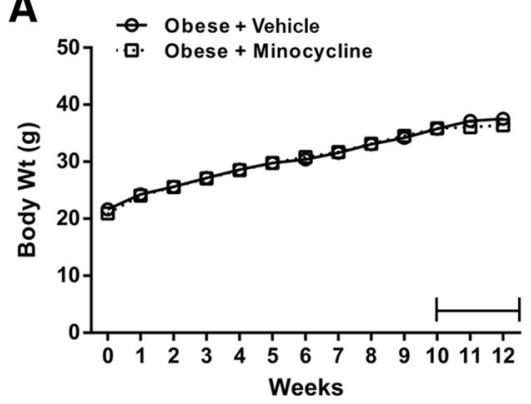

D

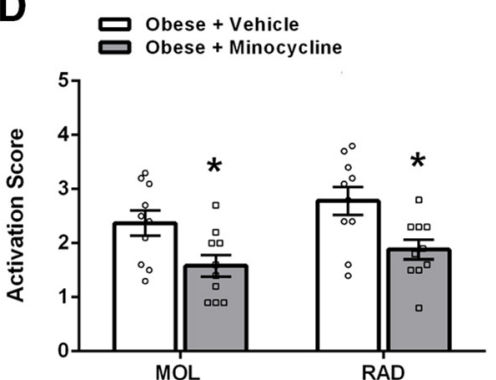

B

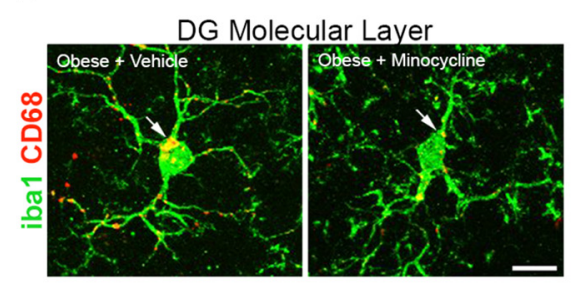

E

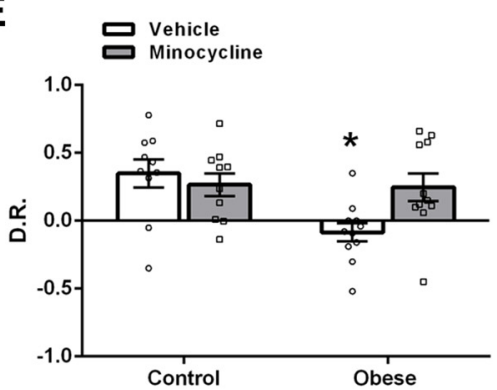

C

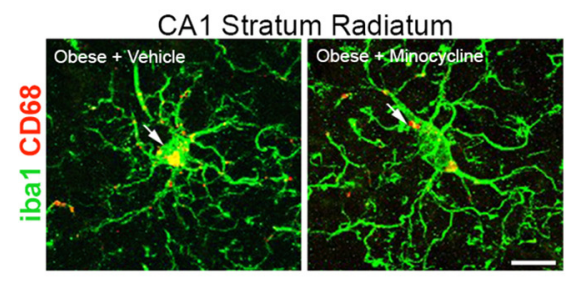

$\mathbf{F}$

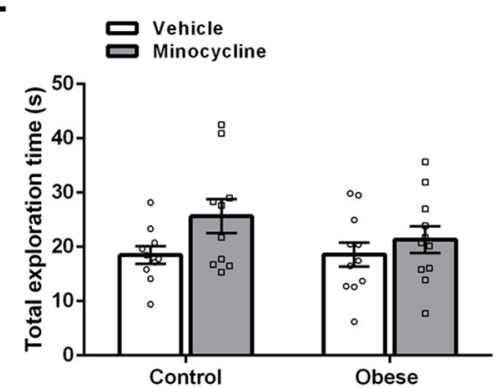

Figure 7. Minocycline treatment prevents obesity-associated microglial activation and cognitive decline. $\boldsymbol{A}$, Weekly body weight measurements for mice fed HFD for 12 weeks showed characteristic weight gain with no differences with minocycline treatment $\left(n=20\right.$ for each group, week: $F_{(12,456)}=262.2, p<0.0001$; treatment group: $F_{(1,38)}=0.051, p=0.82 ;$ and week $\times$ treatment: $F_{(12,456)}=0.64, p=0.81$, two-way ANOVA). Bracket indicates the duration of minocycline treatment. The MOL of the DG $(\boldsymbol{B})$ and the RAD $(\boldsymbol{C})$ of the $C A 1$ region immunolabeled with iba1 (green) and CD68 (red). Scale bar, $10 \mu \mathrm{m}$. Arrows indicate CD68 and iba 1 colabeling. D, Microglial mean activation scores in the M0L $\left(t_{(18)}=2.60, p=0.018\right.$, unpaired $t$ test) and RAD $\left(t_{(18)}=2.84\right.$, $p=0.011$, unpaired $t$ test) of the hippocampus were reduced with minocycline treatment. $N=10$ for each group (10 cells were averaged per animal). $\boldsymbol{E}$, 0 besity-induced impairments in DRs in the $0 \mathrm{~L}$ test were improved by minocycline treatment in obese mice (diet group: $F_{(1,38)}=6.38, p=0.016$; treatment group: $F_{(1,38)}=1.94, p=0.17 ;$ and diet $\times$ treatment: $F_{(1,38)}=5.38, p=0.026$, two-way ANOVA). Holm-Sidak post hoc comparisons show a lower DR in obese + vehicle compared with control + vehicle $\left(t_{(38)}=3.43, p=0.009\right)$, control + minocycline $\left(t_{(38)}=2.77, p=\right.$ $0.042)$, and obese + minocycline $\left(t_{(38)}=2.69, p=0.042\right) . F$, While time spent exploring the objects during the test phase of $0 \mathrm{~L}$ was altered by minocycline treatment (diet group: $F_{(1,38)}=0.75$, $p=0.39$; treatment group: $F_{(1,38)}=4.21, p=0.047$; and diet $\times$ treatment: $F_{(1,38)}=0.84, p=0.36$, two-way ANOVA), Holm-Sidak post hoc comparisons did not reveal any differences between groups. $\boldsymbol{E}, \boldsymbol{F}, n=10$ for control + vehicle and control + minocycline, and $n=11$ for obese + vehicle and obese + minocycline. Error bars indicate SEM. ${ }^{*} p<0.05$ compared with untreated obese mice $(\boldsymbol{D})$ or compared with all other groups $(\boldsymbol{E})$.

treatment group: $F_{(1,38)}=6.51, p=0.015$, and diet $\times$ treatment: $F_{(1,38)}=4.76, p=0.035$, two-way ANOVA, Holm-Sidak post hoc comparisons show differences between obese + minocycline and all other groups [control + vehicle: $p<0.0001$, control + minocycline: $p<0.0001$, and obese + vehicle: $p=0.0058]$ ), there was no difference between groups in the time spent exploring the objects during the test phase (Fig. $7 F$ ). Together, these findings suggest that minocycline improves cognition in obese mice, coincident with reductions in microglial activation, but not in nonobese mice which lack activated microglia.

\section{Minocycline treatment prevents loss of dendritic spines in obese mice}

To determine whether minocycline treatment prevented obesityassociated dendritic spine loss, we also examined dendritic spine density in control and obese mice treated with minocycline. Obese mice had reduced dendritic spine numbers on dendrites of GCs and on apical dendrites of CA1 pyramidal neurons, consistent with our first observations. Compared with untreated obese mice, minocycline-treated obese mice had more spines on dendrites of GCs (Fig. 8A,C) as well as on CA1 pyramidal neuron apical dendrites (Fig. 8B,D). Furthermore, spine density numbers were similar between nonobese control and obese mice treated with minocycline. There was no effect of minocycline treatment on dendritic spine density on either GCs or CA1 pyramidal cells in nonobese controls.

Minocycline treatment has been shown to increase the number of new neurons in mice after brain injury, presumably through its ability to block microglial activation (Liu et al., 2007).
Thus, it is possible that minocycline treatment could improve behavior independently of changes in dendritic spine number, potentially by increasing the number of new neurons. However, obese mice treated with minocycline had similar densities of DCX-positive cells as untreated obese mice (obese: 24,878 \pm 1743 cells per $\mathrm{mm}^{3}$, obese + minocycline: $24,146 \pm 1324$ cells per $\mathrm{mm}^{3}, t_{(17)}=0.34, p=0.74$, unpaired $t$ test); thus, it is more likely that minocycline treatment improves cognitive performance by restoring dendritic spine number.

\section{Annexin-V treatment blocks microglial phagocytosis and prevents obesity-associated cognitive decline}

Activated microglia produce cytokines that can directly influence synapses (Kondo et al., 2011). Thus, from our $\mathrm{C} \times 3 \mathrm{cr} 1^{+/-}$and minocycline experiments, we cannot rule out the possibility that microglia are degrading synapses through inflammatory factors. To investigate whether microglia are eliminating synaptic material by premature synaptic engulfment, we blocked the phagocytic activity of microglia using the drug annexin-V. Annexin-V prevents engulfment by binding phosphatidylserine residues, an "eat me" signal that has been shown to be exposed on degenerating synaptic membranes (Gylys et al., 2004). Because previous work has shown that intravenous administration of annexin- $\mathrm{V}$ crosses the blood-brain barrier (Yagle et al., 2005), obese mice received such injections after 11 weeks of HFD. Annexin-V treatment did not alter obesity levels as there were no differences in body weight at any time point (Fig. 9A) or in abdominal fat weights (obese + saline: $2.75 \pm 0.23 \mathrm{~g}$, obese + annexin-V: $2.67 \pm 0.21 \mathrm{~g}, t_{(38)}=0.24$, 
A

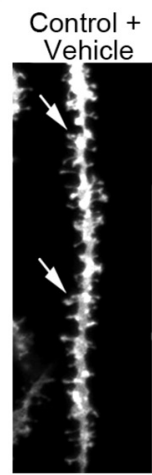

Control +
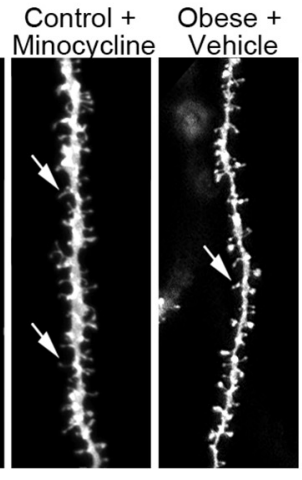

Obese +

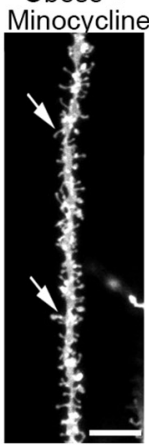

C

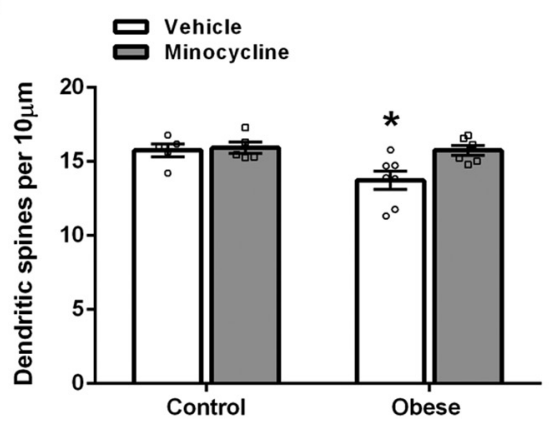

B

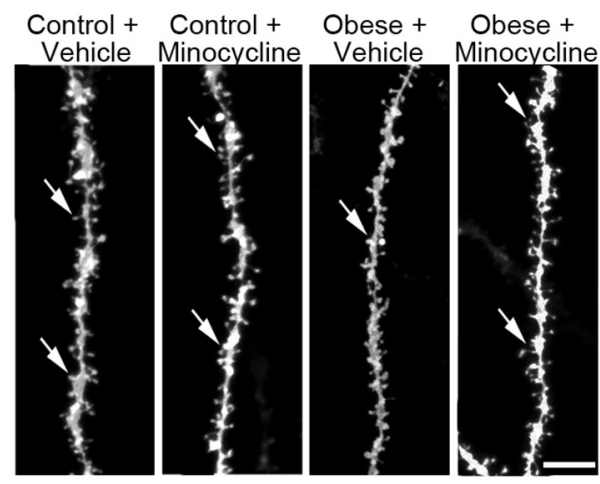

D

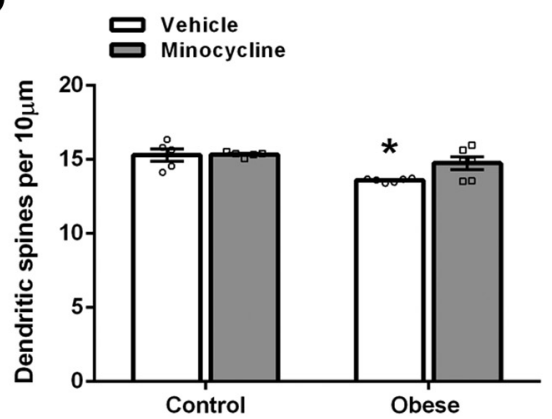

Figure 8. Minocycline treatment prevents obesity-associated dendritic spine loss. Images of dendritic segments labeled with Dil on dendrites of DG GCS $(\boldsymbol{A})$ and on apical dendrites (B) of CA1 pyramidal cells from control and obese mice treated with minocycline. Scale bar, $5 \mu \mathrm{m}$. Arrows indicate dendritic spines. $C$, Obesity-induced decreases in dendritic spine density on $\mathrm{GC}$ dendrites of the DG were increased in minocycline-treated obese mice (diet group: $F_{(1,19)}=5.01, p=0.037$; treatment group: $F_{(1,19)}=4.91, p=0.039$; and diet $\times$ treatment: $F_{(1,19)}=3.56, p=0.075$, two-way ANOVA). Holm-Sidak post hoc comparisons show lower dendritic spine numbers in obese + vehicle compared with control + vehicle $\left(t_{(19)}=2.97, p=0.031\right)$, control + minocycline $\left(t_{(19)}=3.20, p=0.028\right)$, and obese + minocycline $\left(t_{(19)}=3.11, p=0.029\right)$. $D$, Obesity-induced decreases in dendritic spine density on apical dendrites of CA1 pyramidal cells were increased in minocycline-treated obese mice (diet group: $F_{(1,18)}=14.67, p=0.0012$; treatment group: $F_{(1,18)}=3.87, p=0.065$; and diet $\times$ treatment: $F_{(1,18)}=3.42, p=0.081$, two-way ANOVA). Holm-Sidak post hoc comparisons show lower dendritic spine numbers in obese + vehicle compared with control + vehicle $\left(t_{(18)}=4.02, p=0.0041\right)$, control + minocycline $\left(t_{(18)}=4.10, p=\right.$ $0.0040)$, and obese + minocycline $\left(t_{(18)}=2.83, p=0.044\right) . n=5$ for control + vehicle and control + minocycline, $n=7$ for obese + vehicle $(\boldsymbol{D} ; n=6$ for obese + vehicle), and $n=6$ for obese + minocycline (50 spines analyzed per animal). Error bars indicate SEM. ${ }^{*} p<0.05$ compared with all other groups.

$p=0.81$, unpaired $t$ test), between saline and annexin- $\mathrm{V}$ treated groups.

To confirm that annexin- $\mathrm{V}$ blocks microglial engulfment in obese mice, we examined microglial processes within the MOL using immuno-EM. Ultrastructural analyses of membranebound inclusions within ibal-positive microglial processes revealed that annexin- $\mathrm{V}$ blocked phagocytosis such that treated obese mice had fewer inclusions per microglial process (Fig. $9 B, C)$. Indeed, there was an $\sim 25 \%$ reduction in microglial inclusion number in annexin-V-treated obese mice compared with saline-treated obese mice.

Because microglia also engulf new neurons (Sierra et al., 2010), we examined whether blocking phagocytosis altered the number of new neurons in obese mice. There was no difference detected in the density of DCX between groups (obese + saline: $20,159 \pm 941$ cells per $\mathrm{mm}^{3}$; obese + annexin-V: $21,047 \pm 398$ cells per $\mathrm{mm}^{3}, t_{(38)}=1.16, p=0.25$, log transformation followed by unpaired $t$ test).

We next examined whether blocking microglial phagocytosis with annexin- $\mathrm{V}$ treatment alters cognitive performance in control and obese mice. Annexin- $\mathrm{V}$ treatment did not change body weight (control + saline: $30.1 \pm 0.76 \mathrm{~g}$, control + annexin-V: $31.2 \pm 0.48$ g, week: $F_{(2,36)}=0.77, p=0.47$, treatment group: $F_{(1,18)}=2.63, p=0.12$, and week $\times$ treatment: $F_{(2,36)}=0.015$, $p=0.99$, two-way ANOVA) or abdominal fat weights (control + saline: $0.26 \pm 0.07 \mathrm{~g}$, control + annexin-V: $0.26 \pm 0.07 \mathrm{~g}, t_{(18)}=$
0.050, $p=0.96$, unpaired $t$ test) in nonobese controls. As expected, object location testing revealed that saline-treated obese mice had lower DRs compared with nonobese saline-treated controls (Fig. 9D). Annexin-V-treated mice performed better on the OL cognitive test compared with obese mice treated with saline, and their DRs were comparable with that of nonobese salinetreated control mice. There was no difference in OL performance between nonobese controls treated with saline or annexin- $\mathrm{V}$. Furthermore, no differences were detected in total time spent with the objects during testing (Fig. 9E) or in the latency to explore the objects during the familiarization phase (Fig. $9 F$ ) between any group.

Collectively, these findings suggest that annexin- $\mathrm{V}$ improves cognition in obese mice, coincident with reductions in microglial phagocytosis of putative synaptic material, but not in nonobese mice, which lack activated microglia. These findings support our hypothesis that microglial phagocytosis plays a role in obesityassociated cognitive decline.

\section{Discussion}

We show that obesity induced by long-term high-calorie feeding causes cognitive impairment, loss of dendritic spines, and increased microglial activation in brain regions related to cognitive impairment (Bocarsly et al., 2015; Hao et al., 2016). The diet composition used to induce obesity did not matter for cognitive deficits as both long-term HFD and long-term HSD impaired 


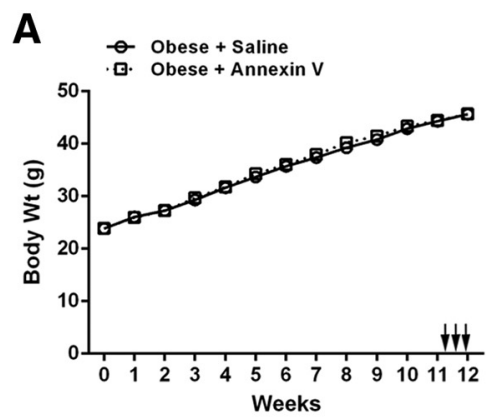

D

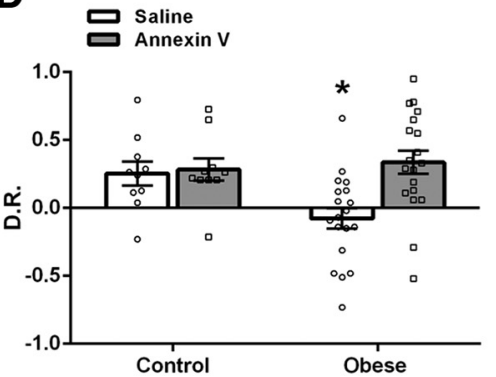

B

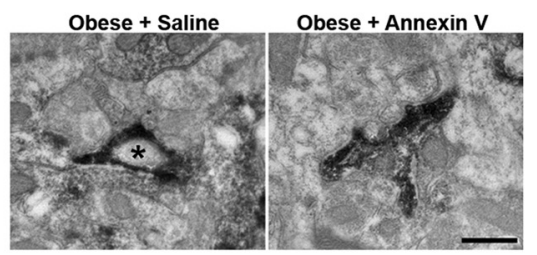

$\mathbf{E}$

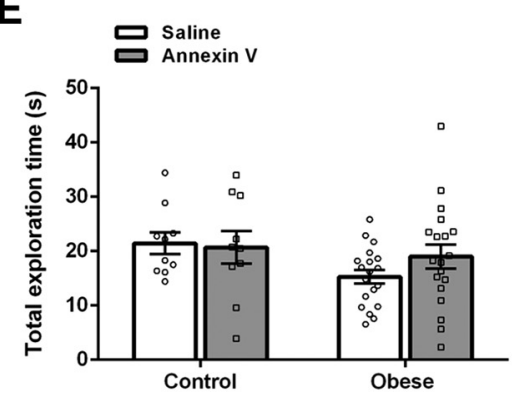

C

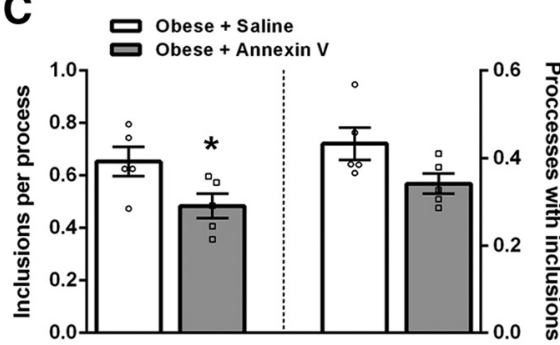

$\mathbf{F}$

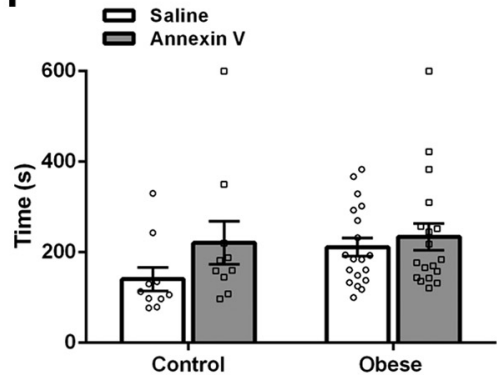

Figure 9. Annexin-V treatment prevents microglial phagocytosis and obesity-associated cognitive decline. $\boldsymbol{A}$, Weekly body weight measurements for mice fed HFD for 12 weeks showed characteristic weight gain with no differences between saline and annexin- $V$ groups $\left(N=20\right.$ for each group, week: $F_{(12,456)}=1806, p<0.0001$; treatment group: $F_{(1,38)}=0.21, p=0.65$; and week $\times$ treatment: $F_{(12,456)}=0.81, p=0.64$, two-way ANOVA). Arrows indicate timing of saline or annexin-V tail vein injections. $B$, EM of microglial processes immunolabeled with iba1 (electron-dense material) from the MOL of the DG. Scale bar, $500 \mathrm{~nm}$. *Large membrane-bound inclusion within a microglial process. C, Left, Ultrastructure analyses of the number of inclusions per iba1-positive process showed decreases in annexin-V-treated obese mice $\left(t_{(8)}=2.33, p=0.048\right.$, unpaired $t$ test). Right, There was no difference between groups in the number iba1-positive processes with putative synaptic inclusions $\left(t_{(8)}=2.08, p=0.072\right.$, unpaired $t$ test). $n=5$ for each group with $42-108$ processes averaged for each animal. $D, 0$ besity-induced impairments in DRs in the $0 \mathrm{~L}$ test were improved by annexin-V treatment in obese mice (diet group: $F_{(1,54)}=2.39, p=0.13$; treatment group: $F_{(1,54)}=6.03, p=0.01$; and diet $\times$ treatment: $F_{(1,54)}=4.54, p=0.038$, two-way ANOVA). Holm-Sidak post hoc comparisons show lower DRs in obese + saline compared with control + saline $\left(t_{(54)}=2.60, p=0.047\right)$, control + annexin-V $\left(t_{(54)}=2.83\right.$, $p=0.032)$, and obese + annexin- $V\left(t_{(54)}=3.90, p=0.0016\right) . E$, Time spent exploring the objects during the test phase of $0 \mathrm{~L}$ was unchanged by diet or by annexin-V treatment $\left(\right.$ diet group: $F_{(1,54)}$ $=3.25, p=0.077$; treatment group: $F_{(1,54)}=0.47, p=0.49$; and diet $\times$ treatment: $F_{(1,54)}=1.07, p=0.31$, two-way ANOVA). $F$, The latency to reach 30 s of exploration with the objects during the familiarization phase of $0 \mathrm{~L}$ was unchanged by diet or by annexin-V treatment (diet group: $F_{(1,53)}=1.81, p=0.18$; treatment group: $F_{(1,53)}=2.72, p=0.10 ;$ and diet $\times$ treatment: $F_{(1,53)}=$ $0.84, p=0.36$, two-way ANOVA). $\boldsymbol{D}-\boldsymbol{F}, n=10$ for control + saline and control + annexin-V, and $n=19$ for obese + saline and obese + annexin-V (in panel $F, n=18$ for obese + annexin-V). ${ }^{*} p<0.05$ compared with saline-treated obese mice $(\boldsymbol{C})$ or compared with all other groups $(\boldsymbol{D})$.

performance on the hippocampus-dependent OL task (Assini et al., 2009; Barker and Warburton, 2011). Obesity was also associated with reduced dendritic spine density on GCs and CA1 pyramidal cells of the hippocampus. In areas of dendritic spine loss, we found increased microglial activation and microglial phagocytosis of putative synaptic elements. We used three approaches to manipulate microglia and found that they were able to disrupt obesity-associated cognitive decline. First, we showed that partial knockdown of the microglial fractalkine receptor prevented obesity-associated cognitive deficits and microglial activation in the hippocampus. Second, we showed that minocycline treatment, an inhibitor of microglial activation, prevented obesityassociated cognitive decline and reduced dendritic spine density. Third, we showed that inhibiting microglial phagocytosis with annexin-V improved cognition in obese mice. It is also worth noting that the microglia manipulations we used did not affect cognitive performance in nonobese mice. Nonobese $\mathrm{C} \times 3 \mathrm{crl}^{+/-}$ mice or nonobese mice treated with minocycline or annexin- $\mathrm{V}$ performed similarly to nonobese WT control mice in the OL task, suggesting that microglia may play a measurable role in cognitive performance only when in an activated state, which occurs in obesity induced by long-term high-calorie feeding. Collectively, our results indicate that microglia are actively involved in obesity-associated dendritic spine loss and cognitive decline.

Our findings showed a relationship between obesity-associated cognitive decline and decreases in the density of dendritic spines, primary sites of excitatory synapses, which have been linked to synaptic plasticity and cognitive function (Yuste and Bonhoeffer, 2001; Yuste, 2011). Restoring dendritic spine density in obese mice to control values with minocycline treatment was associated with restored cognitive function. Furthermore, we did not find decreased neurogenesis in the hippocampus of obese mice, nor did we find that minocycline or annexin- $\mathrm{V}$ treatment altered neurogenesis in obese mice. Together, it is likely that synapse loss, and not reduced neurogenesis, in the hippocampus contributes to obesity-induced cognitive impairment.

These findings have raised questions about potential mechanisms responsible for synapse loss that occurs with long-term high-calorie feeding. Microglia have been shown to eliminate synapses during development (Paolicelli et al., 2011; Schafer et al., 2012). The lysosomal marker CD68, which is often used as a marker of phagocytic function (Ramprasad et al., 1996; Neumann et al., 2009), was increased in microglia actively engulfing synapses during normal development (Schafer et al., 2012). In the hippocampus of obese mice, we observed increased microglial activation and increased putative synaptic inclusions within microglia, specifically in areas of dendritic spine loss. One interpretation of these findings is that microglia play a potentially helpful role in clearing debris resulting from obesity-induced synapse loss. Our studies, however, provide evidence that microglia are causally involved in obesity-associated cognitive dysfunction, presumably through active elimination of functional synapses. Our first line of evidence suggesting this uses the partial knockdown of $\mathrm{Cx} 3 \mathrm{cr} 1$. Our data showed that, when $\mathrm{C} \times 3 \mathrm{cr} 1$ levels are 
lower, microglia did not become activated in the hippocampus in response to long-term high-calorie feeding. Compared with WT nonobese mice, we found reduced microglial activation in Cx3cr1-deficient mice, even in the presence of obesity. This was also associated with a lack of cognitive impairment in obese Cx3crl mice. Early in postnatal development, mice lacking $\mathrm{Cx} 3 \mathrm{cr} 1$ have shown a transient increase in excitatory synapse numbers as a consequence of their failure to properly remove immature synaptic connections (Paolicelli et al., 2011). There is also evidence that $\mathrm{C} \times 3 \mathrm{cr} 1$ deletion may be protective against chronic stress by preventing microglial engulfment of synapses (Milior et al., 2016). The binding between the fractalkine ligand and its receptor can serve as an interface between neurons and microglia (Jung et al., 2000). In response to injury, the soluble form of fractalkine often acts as a chemoattractant to bring microglia to damaged neurons (Harrison et al., 1998). Therefore, reduced neuron-microglia signaling from $\mathrm{Cx} 3 \mathrm{cr} 1$ deficiency may be limiting the ability of microglia to undergo phagocytosis of functional synapses in the obese brain, although future work is necessary to confirm this possibility. It is worth noting that the current literature has conflicting evidence as to whether $\mathrm{Cx} 3 \mathrm{cr} 1$ deficiency increases or reduces microglial activation under neuroinflammatory conditions (Cardona et al., 2006; Lee et al., 2010; Lauro et al., 2015), although our data suggest that Cx3cr1 deficiency is protective against obesity-associated microglial activation and cognitive decline.

An additional line of evidence is that minocycline restores performance in the OL test in obese mice and against obesityassociated dendritic spine loss. Minocycline has been shown to attenuate the neurotoxic effects of microglia in conditions associated with increased neuroinflammation, such as stress (Hinwood et al., 2013; McKim et al., 2016), early life infection (Williamson et al., 2011), brain injury (Liu et al., 2007), and Alzheimer's disease (Seabrook et al., 2006). In aged, but otherwise healthy mice, minocycline treatment has been shown to enhance performance on hippocampal memory tests, an effect associated with increased dendritic spine numbers (Jiang et al., 2015). During the peak developmental period of synapse elimination, minocycline treatment decreased microglial activation and prevented microglial engulfment of synapses (Schafer et al., 2012). We verified that minocycline treatment prevented microglial activation and dendritic spine loss in the hippocampus of obese mice. It seems likely that higher spine density and improved cognitive performance in minocycline-treated obese mice compared with nontreated obese mice are directly related to disrupted microglial activation. In addition to its anti-inflammatory actions, minocycline has been shown to have other neuroprotective effects, such as preventing apoptosis and acting as an antioxidant (Orsucci et al., 2009; Plane et al., 2010; Shultz and Zhong, 2017). We, however, did not find that minocycline administration in nonobese mice altered dendritic spine density or cognitive function, suggesting that its actions may be specific to conditions in which microglia are activated, such as with obesity. From our studies, we cannot ascertain how minocycline reduces microglial activation in the obese brain. It is possible that minocycline reduces $\mathrm{C} \times 3 \mathrm{cr} 1$ expression and/or neuron-microglia signaling, resulting in dampened microglial activation in obesity, although future work is needed to determine whether the effects of Cx3cr1 deficiency and minocycline on obesity-induced microglial activation work through similar or different mechanisms.

Our Cx3cr1 and minocycline studies do not allow us to exclude the possibility that microglia actively eliminate dendritic spines in the obese brain first by releasing damaging cytokines that render synapses inoperable and only secondarily by engulfing the synaptic debris. To address this, we used a drug known to block microglial phagocytosis, annexin-V; it binds to phosphatidylserine residues, an "eat me" signal that is expressed on dying cells (Brown and Neher, 2014) and synapses (Gylys et al., 2004). Therefore, annexin- $V$ treatment prevents recognition and engulfment by microglia (Derecki et al., 2012). First, we verified that annexin- $\mathrm{V}$ reduced microglial phagocytosis by showing that it decreased putative synaptic inclusions located in microglial processes in the hippocampus of obese mice. Next, we assessed its effects on cognitive function and found that blocking microglial phagocytosis with annexin- $\mathrm{V}$ prevented cognitive decline in obese mice. From our studies, we cannot directly determine whether synapses spared from microglial engulfment by annexin- $V$ treatment had already died. The fact that the annexin- $V$ treatment prevented both obesity-induced synaptic engulfment as well as cognitive decline strongly suggests that obesity induces premature engulfment of functional synapses.

While our EM studies indicate an increase in putative synaptic inclusions within microglial processes of obese mice, we were unable to obtain convincing confocal microscopic evidence of increased internalization of synaptic proteins, including synaptophysin and PSD-95, by microglia in obese mice. It is likely that high-calorie diet-induced synapse loss occurs over many days, and even weeks, leading to measurable decreases in dendritic spine numbers. During this time, microglia may be continuously engulfing and rapidly degrading synaptic material (Peri and Nüsslein-Volhard, 2008), so there may only be a brief window of time between phagocytosis of synapses and their digestion by microglia. Consistent with this and previous reports (Schafer et al., 2012; Milior et al., 2016), our ultrastructure analyses revealed that only in a small portion of microglial inclusions were intact synaptic structures identifiable, suggesting that, once internalized, synaptic material degrades rapidly. The possibility also exists that the microglial degradation rate of synaptic proteins may be faster in conditions, such as obesity, in which microglia are more activated.

Our findings suggest that microglia play an active role in obesity-associated cognitive decline, thus providing a potential therapeutic target for mitigating the deleterious effects of obesity on brain function. It may be that after long-term high-calorie feeding leading to obesity, microglia shift to a pathological state where they prematurely deplete synaptic numbers in brain regions critical for cognitive function. Future work is needed to elucidate the cellular and molecular processes that trigger microglial activation and premature engulfment of otherwise functional synapses.

\section{References}

Aguzzi A, Barres BA, Bennett ML (2013) Microglia: scapegoat, saboteur, or something else? Science 339:156-161. CrossRef Medline

Aldskogius H, Liu L, Svensson M (1999) Glial responses to synaptic damage and plasticity. J Neurosci Res 58:33-41. CrossRef Medline

Assini FL, Duzzioni M, Takahashi RN (2009) Object location memory in mice: pharmacological validation and further evidence of hippocampal CA1 participation. Behav Brain Res 204:206-211. CrossRef Medline

Ayala JE, Samuel VT, Morton GJ, Obici S, Croniger CM, Shulman GI, Wasserman DH, McGuinness OP (2010) Standard operating procedures for describing and performing metabolic tests of glucose homeostasis in mice. Dis Model Mech 3:525-534. CrossRef Medline

Bach ME, Hawkins RD, Osman M, Kandel ER, Mayford M (1995) Impairment of spatial but not contextual memory in CaMKII mutant mice with a selective loss of hippocampal LTP in the range of the theta frequency. Cell 81:905-915. CrossRef Medline 
Barker GR, Warburton EC (2011) When is the hippocampus involved in recognition memory? J Neurosci 31:10721-10731. CrossRef Medline

Beydoun MA, Beydoun HA, Wang Y (2008) Obesity and central obesity as risk factors for incident dementia and its subtypes: a systematic review and meta-analysis. Obesity Rev 9:204-218. CrossRef Medline

Bocarsly ME, Fasolino M, Kane GA, LaMarca EA, Kirschen GW, Karatsoreos IN, McEwen BS, Gould E (2015) Obesity diminishes synaptic markers, alters microglial morphology, and impairs cognitive function. Proc Natl Acad Sci U S A 112:15731-15736. CrossRef Medline

Brown GC, Neher JJ (2014) Microglial phagocytosis of live neurons. Nat Rev Neurosci 15:209-216. CrossRef Medline

Cardona AE, Pioro EP, Sasse ME, Kostenko V, Cardona SM, Dijkstra IM, Huang D, Kidd G, Dombrowski S, Dutta R, Lee JC, Cook DN, Jung S, Lira SA, Littman DR, Ransohoff RM (2006) Control of microglial neurotoxicity by the fractalkine receptor. Nat Neurosci 9:917-924. CrossRef Medline

Chung WS, Clarke LE, Wang GX, Stafford BK, Sher A, Chakraborty C, Joung J, Foo LC, Thompson A, Chen C, Smith SJ, Barres BA (2013) Astrocytes mediate synapse elimination through MEGF10 and MERTK pathways. Nature 504:394-400. CrossRef Medline

Cournot M, Marquié JC, Ansiau D, Martinaud C, Fonds H, Ferrières J, Ruidavets JB (2006) Relation between body mass index and cognitive function in healthy middle-aged men and women. Neurology 67:1208-1214. CrossRef Medline

Derecki NC, Cronk JC, Lu Z, Xu E, Abbott SB, Guyenet PG, Kipnis J (2012) Wild-type microglia arrest pathology in a mouse model of Rett syndrome. Nature 484:105-109. CrossRef Medline

Fields RD, Woo DH, Basser PJ (2015) Glial regulation of the neuronal connectome through local and long-distant communication. Neuron 86: 374-386. CrossRef Medline

Fox GB, Fan L, LeVasseur RA, Faden AI (1998) Effect of traumatic brain injury on mouse spatial and nonspatial learning in the Barnes circular maze. J Neurotrauma 15:1037-1046. CrossRef Medline

Franklin KB, Paxinos G (2008) The mouse brain in stereotaxic coordinates. New York: Elsevier Science.

Glendinning JI, Breinager L, Kyrillou E, Lacuna K, Rocha R, Sclafani A (2010) Differential effects of sucrose and fructose on dietary obesity in four mouse strains. Physiol Behav 101:331-343. CrossRef Medline

Golde WT, Gollobin P, Rodriguez LL (2005) A rapid, simple, and humane method for submandibular bleeding of mice using a lancet. Lab Anim 34:39-43. CrossRef Medline

Gunstad J, Paul RH, Cohen RA, Tate DF, Spitznagel MB, Gordon E (2007) Elevated body mass index is associated with executive dysfunction in otherwise healthy adults. Compr Psychiatry 48:57-61. CrossRef Medline

Gylys KH, Fein JA, Wiley DJ, Cole GM (2004) Rapid annexin-V labeling in synaptosomes. Neurochem Int 44:125-131. CrossRef Medline

Hao S, Dey A, Yu X, Stranahan AM (2016) Dietary obesity reversibly induces synaptic stripping by microglia and impairs hippocampal plasticity. Brain Behav Immun 51:230-239. CrossRef Medline

Harrison JK, Jiang Y, Chen S, Xia Y, Maciejewski D, McNamara RK, Streit WJ, Salafranca MN, Adhikari S, Thompson DA, Botti P, Bacon KB, Feng L (1998) Role for neuronally derived fractalkine in mediating interactions between neurons and CX3CR1-expressing microglia. Proc Natl Acad Sci U S A 95:10896-10901. CrossRef Medline

Heyward FD, Walton RG, Carle MS, Coleman MA, Garvey WT, Sweatt JD (2012) Adult mice maintained on a high-fat diet exhibit object location memory deficits and reduced hippocampal SIRT1 gene expression. Neurobiol Learn Mem 98:25-32. CrossRef Medline

Hill JO, Peters JC (1998) Environmental contributions to the obesity epidemic. Science 280:1371-1374. CrossRef Medline

Hinwood M, Tynan RJ, Charnley JL, Beynon SB, Day TA, Walker FR (2013) Chronic stress induced remodeling of the prefrontal cortex: structural re-organization of microglia and the inhibitory effect of minocycline. Cereb Cortex 23:1784-1797. CrossRef Medline

Hwang LL, Wang CH, Li TL, Chang SD, Lin LC, Chen CP, Chen CT, Liang KC, Ho IK, Yang WS, Chiou LC (2010) Sex differences in high-fat dietinduced obesity, metabolic alterations and learning, and synaptic plasticity deficits in mice. Obesity 18:463-469. CrossRef Medline

Jessberger S, Gage FH (2014) Adult neurogenesis: bridging the gap between mice and humans. Trends Cell Biol 24:558-563. CrossRef Medline

Jiang Y, Liu Y, Zhu C, Ma X, Ma L, Zhou L, Huang Q, Cen L, Pi R, Chen X (2015) Minocycline enhances hippocampal memory, neuroplasticity and synapse-associated proteins in aged C57BL/6 mice. Neurobiol Learn Mem 121:20-29. CrossRef Medline

Jung S, Aliberti J, Graemmel P, Sunshine MJ, Kreutzberg GW, Sher A, Littman DR (2000) Analysis of fractalkine receptor CX(3)CR1 function by targeted deletion and green fluorescent protein reporter gene insertion. Mol Cell Biol 20:4106-4114. CrossRef Medline

Kobayashi K, Imagama S, Ohgomori T, Hirano K, Uchimura K, Sakamoto K, Hirakawa A, Takeuchi H, Suzumura A, Ishiguro N, Kadomatsu K (2013) Minocycline selectively inhibits M1 polarization of microglia. Cell Death Dis 4:525. CrossRef Medline

Kondo S, Kohsaka S, Okabe S (2011) Long-term changes of spine dynamics and microglia after transient peripheral immune response triggered by LPS in vivo. Mol Brain 4:27. CrossRef Medline

Lauro C, Catalano M, Trettel F, Limatola C (2015) Fractalkine in the nervous system: neuroprotective or neurotoxic molecule? Ann N Y Acad Sci 1351:141-148. CrossRef Medline

Lee S, Varvel NH, Konerth ME, Xu G, Cardona AE, Ransohoff RM, Lamb BT (2010) CX3CR1 deficiency alters microglial activation and reduces betaamyloid deposition in two Alzheimer's disease mouse models. Am J Pathol 177:2549-2562. CrossRef Medline

Lepousez G, Csaba Z, Bernard V, Loudes C, Videau C, Lacombe J, Epelbaum J, Viollet C (2010) Somatostatin interneurons delineate the inner part of the external plexiform layer in the mouse main olfactory bulb. J Comp Neurol 11:1976-1994. CrossRef Medline

Li Q, Barres BA (2018) Microglia and macrophages in brain homeostasis and disease. Nat Rev Immunol 18:225-242. CrossRef Medline

Li Y, Dai Q, Jackson JC, Zhang J (2008) Overweight is associated with decreased cognitive functioning among school-age children and adolescents. Obesity 16:1809-1815. CrossRef Medline

Liu Z, Fan Y, Won SJ, Neumann M, Hu D, Zhou L, Weinstein PR, Liu J (2007) Chronic treatment with minocycline preserves adult new neurons and reduces functional impairment after focal cerebral ischemia. Stroke 38:146-152. CrossRef Medline

Malnick SD, Knobler H (2006) The medical complications of obesity. QJM 99:565-579. CrossRef Medline

McKim DB, Niraula A, Tarr AJ, Wohleb ES, Sheridan JF, Godbout JP (2016) Neuroinflammatory dynamics underlie memory impairments after repeated social defeat. J Neurosci Res 36:2590-2604. CrossRef Medline

Milior G, Lecours C, Samson L, Bisht K, Poggini S, Pagani F, Deflorio C, Lauro C, Alboni S, Limatola C, Branchi I, Tremblay ME, Maggi L (2016) Fractalkine receptor deficiency impairs microglial and neuronal responsiveness to chronic stress. Brain Behav Immun 55:114-125. CrossRef Medline

Neumann H, Kotter MR, Franklin RJ (2009) Debris clearance by microglia: an essential link between degeneration and regeneration. Brain 132:288 295. CrossRef Medline

National Institutes of Health (2017) Overweight and obesity statistics. National Institute of Diabetes and Digestive and Kidney Diseases https://www. niddk.nih.gov/health-information/health-statistics/overweight-obesity.

Nimmerjahn A, Kirchhoff F, Helmchen F (2005) Resting microglial cells are highly dynamic surveillants of brain parenchyma in vivo. Science 308: 1314-1318. CrossRef Medline

O'Brien JA, Lummis SC (2006) Diolistic labeling of neuronal cultures and intact tissue using a hand-held gene gun. Nat Protoc 1:1517-1521. CrossRef Medline

Opendak M, Gould E (2015) Adult neurogenesis: a substrate for experiencedependent change. Trends Cogn Sci 19:151-161. CrossRef Medline

Orsucci D, Calsolaro V, Mancuso M, Siciliano G (2009) Neuroprotective effects of tetracyclines: molecular targets, animal models and human disease. CNS Neurol Disord Drug Targets 8:222-231. CrossRef Medline

Paolicelli RC, Bolasco G, Pagani F, Maggi L, Scianni M, Panzanelli P, Giustetto M, Ferreira TA, Guiducci E, Dumas L, Ragozzino D, Gross CT (2011) Synaptic pruning by microglia is necessary for normal brain development. Science 333:1456-1458. CrossRef Medline

Pekny M, Nilsson M (2005) Astrocyte activation and reactive gliosis. Glia 50:427-434. CrossRef Medline

Peri F, Nüsslein-Volhard C (2008) Live imaging of neuronal degradation by microglia reveals a role for v0-ATPase al in phagosomal fusion in vivo. Cell 133:916-927. CrossRef Medline

Petrova R, Garcia AD, Joyner AL (2013) Titration of GLI3 repressor activity by sonic hedgehog signaling is critical for maintaining multiple adult 
neural stem cell and astrocyte functions. J Neurosci 33:17490-17505. CrossRef Medline

Plane JM, Shen Y, Pleasure DE, Deng W (2010) Prospects for minocycline neuroprotection. Arch Neurol 67:1442-1448. CrossRef Medline

Profenno LA, Porsteinsson AP, Faraone SV (2010) Meta-analysis of Alzheimer's disease risk with obesity, diabetes, and related disorders. Biol Psychiatry 67:505-512. CrossRef Medline

Raji CA, Ho AJ, Parikshak NN, Becker JT, Lopez OL, Kuller LH, Hua X, Leow AD, Toga AW, Thompson PM (2010) Brain structure and obesity. Hum Brain Mapp 31:353-364. CrossRef Medline

Ramprasad MP, Terpstra V, Kondratenko N, Quehenberger O, Steinberg D (1996) Cell surface expression of mouse macrosialin and human CD68 and their role as macrophage receptors for oxidized low density lipoprotein. Proc Natl Acad Sci U S A 93:14833-14838. CrossRef Medline

Rezaï X, Faget L, Bednarek E, Schwab Y, Kieffer BL, Massotte D (2012) Mouse $\delta$ opioid receptors are located on presynaptic afferents to hippocampal pyramidal cells. Cell Mol Neurobiol 32:509-516. CrossRef Medline

Rogers JT, Morganti JM, Bachstetter AD, Hudson CE, Peters MM, Grimmig BA, Weeber EJ, Bickford PC, Gemma C (2011) CX3CR1 deficiency leads to impairment of hippocampal cognitive function and synaptic plasticity. J Neurosci Res 31:16241-16250. CrossRef Medline

Saltiel AR, Olefsky JM (2017) Inflammatory mechanisms linking obesity and metabolic disease. J Clin Invest 127:1-4. CrossRef Medline

Schafer DP, Lehrman EK, Kautzman AG, Koyama R, Mardinly AR, Yamasaki R, Ransohoff RM, Greenberg ME, Barres BA, Stevens B (2012) Microglia sculpt postnatal neural circuits in an activity and complementdependent manner. Neuron 74:691-705. CrossRef Medline

Schmidt FM, Weschenfelder J, Sander C, Minkwitz J, Thormann J, Chittka T, Mergl R, Kirkby KC, Faßhauer M, Stumvoll M, Holdt LM, Teupser D, Hegerl U, Himmerich H (2015) Inflammatory cytokines in general and central obesity and modulating effects of physical activity. PLoS One 10:3. CrossRef Medline

Seabrook TJ, Jiang L, Maier M, Lemere CA (2006) Minocycline affects microglia activation, Abeta deposition, and behavior in APP-tg mice. Glia 53:776-782. CrossRef Medline

Sellner S, Paricio-Montesinos R, Spieß A, Masuch A, Erny D, Harsan LA, Elverfeldt DV, Schwabenland M, Biber K, Staszewski O, Lira S, Jung S, Prinz M, Blank T (2016) Microglial CX3CR1 promotes adult neurogenesis by inhibiting Sirt 1/p65 signaling independent of CX3CL1. Acta Neuropathol Commun 4:102. CrossRef Medline

Shah R, O'Neill SM, Hinkle C, Caughey J, Stephan S, Lynch E, Bermingham K, Lynch G, Ahima RS, Reilly MP (2015) Metabolic effects of CX3CR1 deficiency in diet-induced obese mice. PLoS One 10:e0138317. CrossRef Medline

Shigemoto-Mogami Y, Hoshikawa K, Goldman JE, Sekino Y, Sato K (2014) Microglia enhance neurogenesis and oligodendrogenesis in the early postnatal subventricular zone. J Neurosci Res 34:2231-2243. CrossRef Medline

Shultz RB, Zhong Y (2017) Minocycline targets multiple secondary injury mechanisms in traumatic spinal cord injury. Neural Regen Res 12:702713. CrossRef Medline

Sierra A, Encinas JM, Deudero JJ, Chancey JH, Enikolopov G, OverstreetWadiche LS, Tsirka SE, Maletic-Savatic M (2010) Microglia shape adult hippocampal neurogenesis through apoptosis-coupled phagocytosis. Cell Stem Cell 7:483-495. CrossRef Medline

Smith E, Hay P, Campbell L, Trollor JN (2011) A review of the association between obesity and cognitive function across the lifespan: implications for novel approaches to prevention and treatment. Obes Rev 12:740-755. CrossRef Medline

Snyder JS, Cameron HA (2012) Could adult hippocampal neurogenesis be relevant for human behavior? Behav Brain Res 227:384-390. CrossRef Medline

Snyder JS, Soumier A, Brewer M, Pickel J, Cameron HA (2011) Adult hippocampal neurogenesis buffers stress responses and depressive behaviour. Nature 476:458-461. CrossRef Medline

Thaler JP, Yi CX, Schur EA, Guyenet SJ, Hwang BH, Dietrich MO, Zhao X, Sarruf DA, Izgur V, Maravilla KR, Nguyen HT, Fischer JD, Matsen ME, Wisse BE, Morton GJ, Horvath TL, Baskin DG, Tschöp MH, Schwartz MW (2012) Obesity is associated with hypothalamic injury in rodents and humans. J Clin Invest 122:153-162. CrossRef Medline

Tikka T, Fiebich BL, Goldsteins G, Keinanen R, Koistinaho J (2001) Minocycline, a tetracycline derivative, is neuroprotective against excitotoxicity by inhibiting activation and proliferation of microglia. J Neurosci Res 21:2580-2588. CrossRef Medline

Tremblay MĖ, Lowery RL, Majewska AK (2010) Microglial interactions with synapses are modulated by visual experience. PLoS Biol 8:11. CrossRef Medline

Valdearcos M, Robblee MM, Benjamin DI, Nomura DK, Xu AW, Koliwad SK (2014) Microglia dictate the impact of saturated fat consumption on hypothalamic inflammation and neuronal function. Cell Rep 9:21242138. CrossRef Medline

Valladolid-Acebes I, Fole A, Martín M, Morales L, Cano MV, Ruiz-Gayo M, Del Olmo N (2013) Spatial memory impairment and changes in hippocampal morphology are triggered by high-fat diets in adolescent mice. is there a role of leptin? Neurobiol Learn Mem 106:18-25. CrossRef Medline

Wang CY, Liao JK (2012) A mouse model of diet-induced obesity and insulin resistance. Methods Mol Biol 821:421-433. CrossRef Medline

Wang Y, Zhao Z, Rege SV, Wang M, Si G, Zhou Y, Wang S, Griffin JH, Goldman SA, Zlokovic BV (2016) 3K3A-activated protein C stimulates postischemic neuronal repair by human neural stem cells in mice. Nat Med 22:1050-1055. CrossRef Medline

Ward MA, Carlsson CM, Trivedi MA, Sager MA, Johnson SC (2005) The effect of body mass index on global brain volume in middle-aged adults: a cross sectional study. BMC Neurol 5:23. CrossRef Medline

World Health Organization (2017) Obesity and overweight. http://www. who.int/news-room/fact-sheets/detail/obesity-and-overweight.

Williamson LL, Sholar PW, Mistry RS, Smith SH, Bilbo SD (2011) Microglia and memory: modulation by early-life infection. J Neurosci Res 31: 15511-15521. CrossRef Medline

Xiao F, Xu JM, Jiang XH (2015) CX3 chemokine receptor 1 deficiency leads to reduced dendritic complexity and delayed maturation of newborn neurons in the adult mouse hippocampus. Neural Regen Res 10:772-777. CrossRef Medline

Yagle KJ, Eary JF, Tait JF, Grierson JR, Link JM, Lewellen B, Gibson DF, Krohn KA (2005) Evaluation of $18 \mathrm{~F}$-annexin V as a PET imaging agent in an animal model of apoptosis. J Nucl Med 46:658-666. Medline

Yuste R (2011) Dendritic spines and distributed circuits. Neuron 71:772781. CrossRef Medline

Yuste R, Bonhoeffer T (2001) Morphological changes in dendritic spines associated with long-term synaptic plasticity. Annu Rev Neurosci 24 : 1071-1089. CrossRef Medline

Zhao Y, Xiao M, He W, Cai Z (2015) Minocycline upregulates cyclic AMP response element binding protein and brain-derived neurotrophic factor in the hippocampus of cerebral ischemia rats and improves behavioral deficits Neuropsychiatr Dis Treat 11:507-516. CrossRef Medline 